\title{
MEASURING NURSES' ACCURACY \\ OF ESTIMATING BLOOD LOSS
}

by

Patricia Grant Higgins

\author{
A Thesis Submitted to the Faculty of the \\ COLLEGE OF NURSING \\ In Partial Fulfillment of the Requirements \\ For the Degree of \\ MASTER OF SCIENCE \\ In the Graduate College \\ THE UNIVERSITY OF ARIZONA
}


This thesis has been submitted in partial fulfillment of requirements for an advanced degree at The University of Arizona and is deposited in the University Library to be made available to borrowers under rules of the Library.

Brief quotations from this thesis are allowable without special permission, provided that accurate acknowledgment of source is made. Requests for permission for extended quotation from or reproduction of this manuscript in whole or in part may be granted by the head of the major department or the Dean of the Graduate College when in his judgment the proposed use of the material is in the interests of scholarship. In all other instances, however, permission must be obtained from the author.

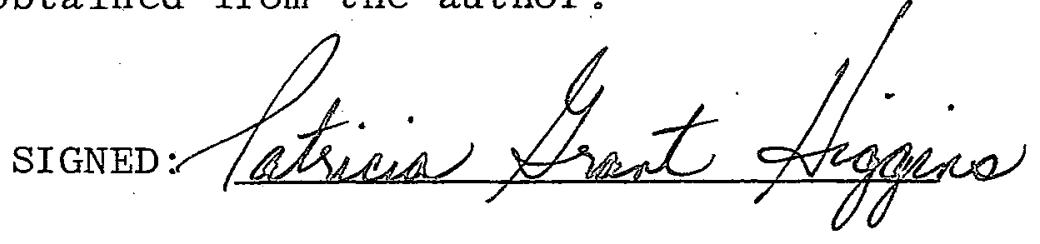

APPROVAL BY THESIS DIRECTOR

This thesis has been approved on the date shown below:

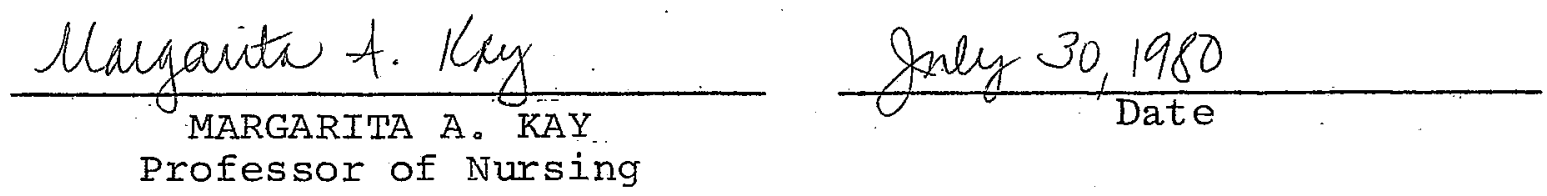




$$
\begin{aligned}
& \text { Love is always unselfish. } \\
& \text { Love is always giving. } \\
& \text { Love is a vital part of my life. }
\end{aligned}
$$

This thesis is lovingly dedicated to my husband, Dr. Cornelius J.Higgins, who gave of himself and became both mother and father so that I could pursue my dreams. He gave me his constant support, endless understanding, and infinite love.

To my children, Eileen, Christopher, and Lorraine, who gave so much of themselves throughout this year so that I could learn to give. They are my love, life, and joy。 
Happy the man who finds wisdom,

the man who gains understanding:

For her profit is better than profit in silver, and better than gold is her revenue,

Proverbs $4: 13-14$

\section{ACKNOWLEDGMENTS}

The author would like to express her sincere appreciation to the members of her thesis committee for their advice and assistance in the process of completing this research. The committee included Margarita A. Kay, chairperson, Sara Stark, and Alice Noyes. I am most grateful for their time and encouragement.

I am sincerely grateful to my husband and children for helping to organize the data in this thesis, and for their time, support, and encouragement.

- Special appreciation is due Mary Ann Schroeder who helped with the statistical analysis of the data and Joan Farmer for her suggestions, support, and typing this thesis. Grateful appreciation is extended to the nurses who participated in the study and to the American Red Cross for saving the outdated blood to be used in the study.

A special thanks is given to my mother, Lottie Grant, who provided encouragement and support throughout this year of graduate study; my brother Michael who gave time during his vacation to help with the data; and my 
brother Timothy who has encouraged me to grow in new dimensions. 
TABLE OF CONTENTS

Page

LIST OF TABLES . . . . . . . . . . . . . . . . viii

LIST OF ILLUSTRATIONS . . . . . . . . . . . . ix

ABSTRACT . . . . . . . . . . . . . . . . $\mathrm{x}$

1. INTRODUCTION . . . . . . . . . . . . . . . . . . 1

Statement of the Problem . . ... . . . . . 2

Purpose of the Study... . . . . . . . . . . . 2

Significance of the Problem . . . . . . . . . 3

Definition of Terms . . . . . . . . . . . . . 6

Conceptual Framework . . . . . . . . . . . . . 7

Neurophysiology of the Cognitive Process . 7

The Cognitive Process . . . . . . . . 11

Cognitive Styles... . . . . . . . 13

2. LITERATURE REVIEW . . . . . . . . . . . . . . 16

Composition of Whole Blood . . . . . . . . 16

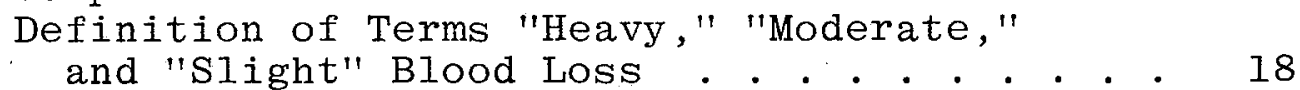

Difficulties of Estimating Blood Loss . . . . . 19

- Methods of Determining Blood Loss . . . . . . 21

Direct Ways of Determining Blood Loss . . 21

Indirect Ways of Determining Blood Loss . 25

3. RESEARCH METHODOLOGY . . . . . . . . . . . 29

Research Design . . . . . . . . . . . . 29

Access to Research Setting . . . . . . . . . 29

Sample and Setting. . . . . . . . . . . . 30

Method of Data Collection . . . . . . . . . 31

Development of the Instrument . . . . . . . 32

Data Analysis . . . . . . . . . . . . 32

4. PRESENTATION AND ANALYSIS OF DATA . . . . . . . 36

Demographic Characteristics

of the Population .. . . . . . . . . . . . 36

Degree of Accuracy in Determining Blood Loss: 41

Data Related to Overestimation and

Underestimation of Blood Loss . . . . . . 51 
TABLE OF CONTENTS--Continued

Page

5. DISCUSSION OF THE STUDY . . . . . . . . . . . 56

Analysis of Data Relating to the Degree

of Accuracy in Estimating Blood Loss . . . 56

What Nurses Consider Heavy, Moderate,

and Slight Blood Loss... . . . . . . . 58

Analysis of Data As It Relates to

Over- and Underestimation . . . . . . . 59

Nursing Implications . . . . . . . . . . . 59

Recommendations for Future Study . . . . . . 62

6. SUMMARY . . . . . . . . . . . . . . . . . 64

Purpose of the Study . . . . . . . . . . . 64

Methodology . . . . . . . . . . . 65

Findings . . . . . . . . . . . . . . . . 66

Conclusions . . . . . . . . . . . . . . . 66

Recommendations . . . . . . . . . . . . 67

APPENDIX A: ETHICAL REVIEW COMMITTEE APPROVAL . 68

APPENDIX B: DISCLAIMER SHEET . . . . . . . . . 69

APPENDIX C: RECORDING SHEET . . . . . . . . 70

APPENDIX D: ANSWERS TO THE 20 ITEMS ON
ESTIMATING BLOOD LOSS . . . . . . . 71

SELECTED BIBLIOGRAPHY . . . . . . . . . . . . 72 


\section{LIST OF TABLES}

Table

Page

1. Summary of Obstetrical Blood Loss Studies . .

2. Age and the Number of Years of Experience in Estimating Blood Loss . . . . . . . . . .

3. Demographic Characteristics of the Sample in Relation to Sex and Education . . . . . . . .

4. Specialty or Work Site Where Nurses Estimate Blood Loss on a Daily Basis . . . . . . .

5. Categorization of Responses As to When Nurses First Learned to Estimate . . . . . .

6. Methods by which Nurses Learn to Estimate

7. Blood on 20 Peripads Estimated as Heavy, Moderate, or Slight $(N=42)$. . . . . . . .

8. Range of Blood Estimated as Heavy, Moderate, or Slight . . . . . . . . . . .

9. Differences between the Actual Amount and Mean Estimate of Blood . . . . . . . . . .

10. Number of Correct Responses Made by 42 Nurses with Pre-measured Blood on 20 Peripads ... .

11. Estimation Percentages and Relationship to Education, Experience, and Specialty Area . .

12. Estimation Percentages and Relationship As to When and How Nurses First Learned to Estimate Blood Loss . . . . . . . . . . 


\section{LIST OF ILLUSTRATIONS}

Figure

Page

1. Major Components of Human Blood . . . . . . . 17

2. Average Error versus Actual Amount of Blood . . 47

3. Percentage of 42 Nurses Who Over- and Underestimate Blood Loss . . . . . . . . . 52 


\section{ABSTRACT}

Estimation is the most commonly used method to determine blood loss. According to the literature, estimating blood loss is not exact; there are wide margins of error, and blood loss tends to be underestimated. Fortytwo registered nurses were asked to estimate varied amounts of blood on 20 peripads. Both over- and underestimation occurred. Of the nurses participating in the study, 71 percent overestimated and 25 percent underestimated blood loss. There was also disagreement as to what constituted heavy, moderate, or slight blood loss. There was no relationship between accuracy and education, years of experience; specialty area, or when and how nurses learned to estimate. In general, the nurses (1) overestimated blood loss, (2) had significant difficulty. in estimating very small and very large amounts of blood, (3) although in error, were consistent in estimating repeated samples with the same amounts of blood, (4) were not consistent in estimating heavy, moderate, and slight blood loss. 
CHAPTER ' 1

\section{INTRODUCTION}

After a woman delivers her baby, the maternity nurse is the one who initially has contact with her and is responsible for her. The nurse fully assesses temperature, pulse, respiration, blood pressure, height of the fundus, and decidual bleeding. This bleeding is usually recorded as heavy, moderate, or slight. If' she judges bleeding to be heavy, the nurse informs the physician. The physician builds the client's care on the nurse's estimation of the blood loss.

When nurses are asked how much blood there is on a given peripad, they often respond by an estimate, saying "heavy," "moderate," or "slight." But how much blood loss is a moderate amount? Estimation is by far the most common method used by nurses and physicians to determine blood 1oss. There are no means available to any health worker initially to assess blood loss other than by subjective individual estimation.

There is a variance in blood loss, as expressed by Greenhill (1965, p。946):

Blood loss in obstetrics varies with each individual client. The amount of blood lost is influenced by the size of the fetus, the area of the placenta, 
its location in the uterus, the rapidity of the separation, strength of uterine contractions and retractions. The method of delivery also influences the amount of blood loss as do pathological conditions.

Blood loss also varies with the age of the mother. Blood loss increases with age, especially if the woman is over 35 years. Blood loss is lowest in the 20-24 year age group (Dunn et al。, 1973; Sprague and Nagell, 1974). Plass, Litzenberg, and Calkins (1931), in an older study of 3,000 cases, stated that primigravidas lost more blood than multigravidas and age had no effect on blood loss. Bethea (1973) stated that blood loss also varied; however, multigravidas have more blood loss than primigravidas. These data may or may not influence estimation of amount.

\section{Statement of the Problem}

This study was designed to determine the degree of accuracy exhibited by nurses in determining blood loss.

\section{Purpose of the Study}

The purpose of this study was to attempt to answer the following questions:

1. How accurate are nurses in estimating blood loss?

2. Do nurses tend to overestimate or underestimate blood loss?

3. What is the range, in $c c^{\top} \mathrm{s}$, of blood loss for heavy loss? 
4. What is the range, in $\mathrm{cc}^{\mathrm{i}} \mathrm{s}$, of blood loss for moderate loss?

5. What is the range, in $\mathrm{cc}^{\prime} \mathrm{s}$, of blood loss for slight loss?

It was also the purpose of this study to survey the literature on blood loss estimation and to consider the processes of estimation.

\section{Significance of the Problem}

The problem of estimating blood loss is significant to maternity nursing because it has a direct bearing on the outcome of pregnancy and wellness of the mother. Maternal mortality results from intra- and postpartum hemorrhage, and the amount of blood loss cannot be assessed by vital signs. The maternal mortality rate is declining each year. However, in 1973, the United States Department of Health, Education, and Welfare, in their Vital Statistics Report (Heuser, 1973), stated that the maternal mortality rate per 100,000 live births consisted of 10.7 for whites and 34.6 for all other races. There is a big difference in the maternal mortality rate for non-whites. It is three times higher for non-whites than it is for whites. According to Yordan, Turk, and Petrie (1977), 25-30 percent of maternal deaths continue to result from intra- and postpartum hemorrhage. Elener (1986) stated that 12 percent of maternal death is due to hemorrhage. The incidence of 
hemorrhage is higher in the non-white population and the accuracy that nurses have in estimating blood loss becomes crucial. This study will not be looking at hemorrhage. The accuracy of estimation has a bearing on hemorrhage because a loss of $500 \mathrm{cc}^{\text {'s }}$ of blood may constitute hemorrhage in certain clients.

On the other hand, increased bleeding, particularly in the last trimester of pregnancy, and also during labor, delivery, and postpartum is undoubtedly the most frequently encountered obstetrical emergency and continues to be the leading cause of maternal death in the United States. The varied etiologies of obstetrical hemorrhage are well known and the dangers of postpartum hemorrhage are greatest in the following situations (Alderman, 1975; Aladjem, 1975; Elener, 1968; Louka and Lewis, 1976; and McManus, 1975):

pol yhydramnios multiple pregnancy

history of grand multiparity

history of postpartum hemorrhage prolonged labor placentá previa abruptio placenta uterine atony hematomas after episiotomy and pudendal blocks trauma caesarean section traumatic delivery large baby (over 9 pounds) oxytocin induction ruptured marginal sinus uterine inversion ruptured placenta lacerations retained placenta retained secundines hypofibrinogenemia 
The significance of bleeding in maternity nursing is well established. But the degree of danger, that is. the amount of blood loss, cannot be assessed by vital signs. According to Stromme (1976), during the later part of pregnancy the average woman can lose up to $1,500 \mathrm{ml}$ of blood before there is a significant drop in blood pressure, but a relatively small amount of additional bleeding can cause a severe drop. Vital signs need to be interpreted intelligently. The pulse rate may increase only a point or so at each recording. One needs to look at the entire picture or one will miss the fact that although the pulse is rising slowly, it is continuous. In a "slow bleed," blood is being lost in small quantities over a 24-hour period or even up to a few days before it is truly noticed. The circulatory system compensates in the same manner; therefore, there may be very little change in vital signs. Moreover, the amount of blood loss which constitutes a hemorrhage, especially postpartum hemorrhage, is not clearly defined. There are many individual factors, and the exact amount of blood loss to be classified as hemorrhage is unclear (Modan, Kumar, and Misra, 1967). By attempting to define the ambiguous terms of "heavy," "moderate," or "slight," this study may make maternity nursing more scientific. Nurses are well aware that the third and fourth stages of labor can "indeed be most unforgiving and lurk more unheralded treachery 
than in the other stages of labor combined" (McManus, 1975, p.70). The normal case can, within a minute, become abnormal and a successful delivery can swiftly turn to disaster。

\section{Definition of Terms}

The following terms were defined for clarity of use in this study:

1. Estimation--A cognitive process by which a nurse subjectively, visually assesses a specific amount of blood on a peripad.

2. Blood loss--The amount of blood in $\mathrm{cc}$ 's that is subjectively estimated on a peripad and stated as heavy, moderate, or slight. It consists of whole blood and its constituents from any body part or surface area.

3. Lochia or decidual blood--Both terms are used synonymously. Described as blood loss from the endometrial lining of the uterus seen at delivery and in the postpartum period.

4. Outdated whole blood-Federal standards state that blood is outdated if it is not used within 21 days after being drawn.

5. Nurse--A licensed registered nurse who is a graduate of an associate degree, diploma, or baccalaureate program. 


\section{Conceptual Framework}

The conceptual framework for this study is based on the concepts of the physiological processing of perceived information and the cognitive process and styles from psychology。 These concepts are interrelated to determine the processes that one goes through in accurately estimating blood loss.

Neurophysiology of the Cognitive Process

Bartlett (1932), Tolman (1938), and Piaget (1950) became associated with the argument that we are not just passive receivers of stimuli and producers of responses. Learning, they argued, is an active process which involves the use of "strategies and the transformation of sensory experience into new categories and organized conceptions" (Wingfield, 1979, p。15)。Cognition came to be used as a general term to describe those mental processes which transform sensory input in various ways, code it, store it in memory, and retrieve it for later use. Since human learning involves active responding, organizing, and reorganizing material, human learning almost always involves some kind of cognitive activity (Ellis, 1972)。 Tolman (1948) gave cognitive learning an experimental base. He argued that all higher organisms, from man to rats, form cognitive maps in their minds--today often referred to by the term "cognitive learning。" 
Cognitive psychology later rejected the narrowness of this so-called stimulus-response view of human activity, setting as its goal a no less objective and scientific study of behavior, but one which would hope to provide understanding and explanation of those internal mental states which lie between the stimuli and responses. Cognitive psychology uses the principles of behavior as a means to an end of understanding internal events, strategies, and cognitive processes which give rise to this behavior (Wingfield, 1979)。

The brain is the seat of human intellect; motivation, and learning. Logic tells us that learning must cause some physiological changes in the brain because we can retain what we learn and these changes must be permanent. The subject matter is indeed complex and much of what we need to know about brain function in cognitive processes has yet to be discovered. More is known about the brain's reception of light and sound and the control of motor movements than is known about its role in complex learning, memory, thought, and estimation。

The human brain, or cerebrum; is constructed as two physically identical halves, known as hemispheres. The split brain theory, or the lateralization theory, states that each hemisphere of the brain is responsible for certain mental abilities. The left side of the brain is involved with logic and verbal functions. The right side of the 
brain is involved with intuitive, emotional, and spatial abilities (Duman and Morgan, 1975)。 It may be assumed that both sides of the brain are involved in the estimation process and the accuracy of each nurse in determining the amount of blood on a peripad. The spatial abilities of the right-side must coordinate with the logical functions of the left side for the estimation process to occur. The outer surface of the hemispheres is the cortex, which is involved in intellectual and voluntary control. The cortex is also involved in the estimation process.

The key to cognitive processes, such as perception, learning, memory, and estimation, lies in the action of 10 billion microscopic brain cells called "neurons." Neurons consist of a cell body which keeps the cell alive and nourished, dendrite fibers which carry impulses from neighboring neurons to the cell body, and an axon fiber which transmits impulses away from the cell body to other neurons。

The axon of one neuron and the dendrites of others are separated by tiny gaps called "synapses," with activation of neighboring neurons accomplished through release of a chemical transmitter substance which allows the impulse to travel across these synaptic gaps。 Such transmitter substances include acetylcholine, norepinephrine, and serotonin along with their chemical inhibitors which 
terminate transmission once the neighboring cells have been stimulated。

An early attempt to conceptualize the physiological basis of cognitive processes was made by Hebb (1949), who saw the cognitive process of learning represented by the facilitation of different sequences of neuronal stimulation in the form of new pathways of impulse travel among preexisting neurons. Short-term memory could be represented as the transient formation of reverberating circuits which are highly susceptible to interference and require time for consolidation into long-term memory。

A current view of memory consolidation sees the formation of long-term traces as a consequence of chemical changes within the neurons themselves, causing the cell to remember its position in a particular neuronal sequence. The physiological basis of memory is seen as primarily chemical, brought about by changes in the structure of ribonucleic acid (RNA) within the cell bodies which controls the formation of specific proteins to regulate synaptic transmission (Wingfield, 1979)。

Estimation, according to the literature, has not yet received detailed analysis within the cognitive processing framework. The true answer of how one estimates blood loss lies within the cortex and in the action of the microscopic nerve cells themselves. However, estimating blood loss in cubic centimeters and stating 
whether the blood loss is heavy, moderate, or slight depends on complex interrelationship of perception, judgment, cognitive style, and integration of this entire cognitive process by the nervous system. The cognitive process of estimating blood loss on peripads based on neurophysiology can be summarized simply as follows: A peripad with a set amount of blood gives off energy that stimulates a sense organ (the eye), the sense organ codes the energy into the language of nerve activity; this activity is conveyed to the brain, where it is processed, resulting in a perception of the object and estimated as heavy, moderate, or slight。 This model will now be discussed.

\section{The Cognitive Process}

Cognitive theorist Van Foerster (1970) stated that mental processes such as learning, perceiving, and estimating are part of "cognition." One cannot separate these processes and study only one aspect of cognition alone because the processes are interrelated. As a total part of the cognitive process, each aspect utilized together maintains the integrity of the organism as a functioning unit. Today, this "integrity-of-cognition principle" leads to generalities that apply across the traditionally separate psychological faculties. It implies that input from stimulation, output from memory, and the sheer constructions of imagination all.pass through the same 
experimental level at some point, and that there they are all subject to the same central psychological processes (Blumenthal, 1977).

The sensory processing arises from stimulation of endorgans and involves much more than the straightforward relay of sensory-evoked impulses to higher brain centers. A necessary part of that processing demands that comparisons be made with memory stores in order for a recognizable sensation to be encountered. There are many sensory signals that do not reach consciousness. Perception, as part of the cognitive process, involves subjective awareness and makes up an internal model of our world. Perception is an ongoing experience in consciousness related to behavior. Perception includes total mental contents including images as we see them from the stimuli that are presented. One can also call upon consciousness from past experience or prior images (Livingston, 1978). Perception also allows us to arrive at conscious judgments in our perceptual apparatus: we perceive what is the best choice or best answer or amount of blood lost among options available to us. Everything that we are conscious of comes together in perception.

Quantitative judgments are one of man's most important cognitive skills。 Klahr and Wallace (1976) argue that there are only three distinct quantitative mechanisms underlying most of the vast variety of 
situations in which man makes quantitative judgments, counting, and estimation. Counting refers to mechanisms for ascertaining numerical quantity, whereas estimation can be used to make judgments of either numerical or continuous quantity. It is generally assumed that estimations are based on perceptual features such as length, density, and area。

Piaget (1965) is the only one from the literature to consider estimation as an entire topic within itself. He has shown that estimation overrides counting in young children because, even though children are able to count, they are likely to be misled by sensory properties, resulting in failures to conceptualize number. This tendency to rely on estimation rather than on more abstract logical processes is also the basis for young children's failure to conceptualize volume, weight, and substance.

\section{Cognitive Styles}

The way in which one perceives and estimates depends on individual variations in cognitive approaches and differences in cognitive style (Kagen and Kagen, 1970)。

Most of us do better on tests of certain mental abilities than of others. Over the past two decades, researchers have discovered that people tend to have distinctive and relatively consistent patterns of thinking, 
perceiving, and problem-solving. These tendencies are known as cognitive styles (Rice, 1979).

Convergent versus divergent. Convergent thinkers are those people who tend to reach logical conclusions based on reasoning and do well in scientific activities. They do better on multiple choice tests that require them to find the one correct answer. Divergent thinkers are those people who tend to be more creative and are suited to open-ended questions that allow a number of alternative possibilities. Convergent thinkers base their reasoning on the deductive process while divergent thinkers base their reasoning on the inductive process (Rice, 1979).

\section{Field independent versus field dependent. Field} independent people concentrate on the big picture and think independently of the surrounding context or "field". They do well at tasks requiring logical ability and are somewhat impersonal and insensitive to social surroundings. Field dependent is just the opposite. These people concentrate on internal details. They are less analytical, more socially perceptive, and subject to external influences. According to Rice (1979), the two types can be differentiated by the use of the "Embedded Figure Test." This test measures the visual ability to distinguish figures from similarly textured backgrounds. 
Scanning versus focusing. According to Rice (1979), scanners go "meticulously" through all the details of a situation--including incidental ones--for uniform details, ignoring peripheral cues that might be important. To differentiate between scanners and focusers, researchers use written descriptions or videotaped portrayals of. complex social situations in order to assess and form a correct impression of the situation.

\section{Masculine versus feminine. Cognitive styles} between men and women are based on culture and childrearing and, in part, differences in brain-hemisphere dominance. Men tend to have better spatial ability and perform better on tasks requiring simultaneous use of more than one mental skill. Women focus attention on one particular task and have better verbal ability。

Cognitive styles influence human activities, including social behavior and personality. People who become aware of their own cognitive styles may be abie to develop and use problem-solving strategies. Cognitive styles are included in the framework to determine the existence of a relationship between those people who underestimate and those who overestimate. 
CHAPTER 2

\section{LITERATURE REVIEW}

The literature was reviewed for the purpose of presenting information from previous investigations of the following:

1. Composition of whole blood.

2. Definition of the terms "heavy," "moderate," and "slight" blood loss。

3. Difficulties of estimating blood loss.

4. Methods of determining blood loss:

a. Direct ways of determining blood loss.

b. Indirect ways of determining blood loss.

\section{Composition of Whole Blood}

According to Guyton (1971), blood is a viscous fluid composed of cells and plasma. More than 99 percent of these cells are red blood cells. The white blood cells play almost no role in determining the physical characteristics of the blood. Bishop (1974, 1978) broke down the major components of human blood as shown in Figure 1 .

There are many changes in the hemodynamics during pregnancy and the cellular elements in the human blood do change. The major change within the cellular elements is that the platelets increase from $230,000-400,000$ per co mm. 


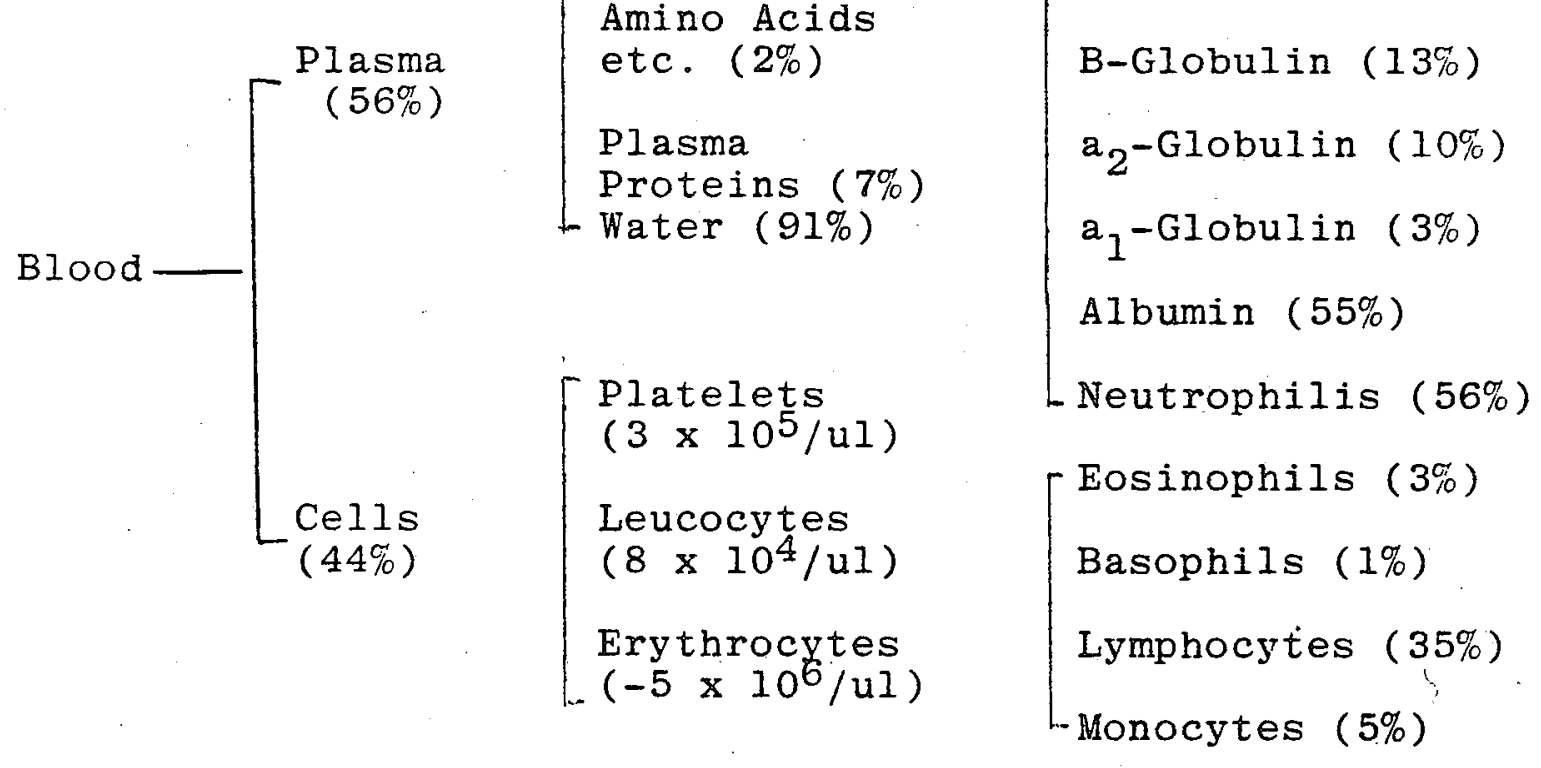

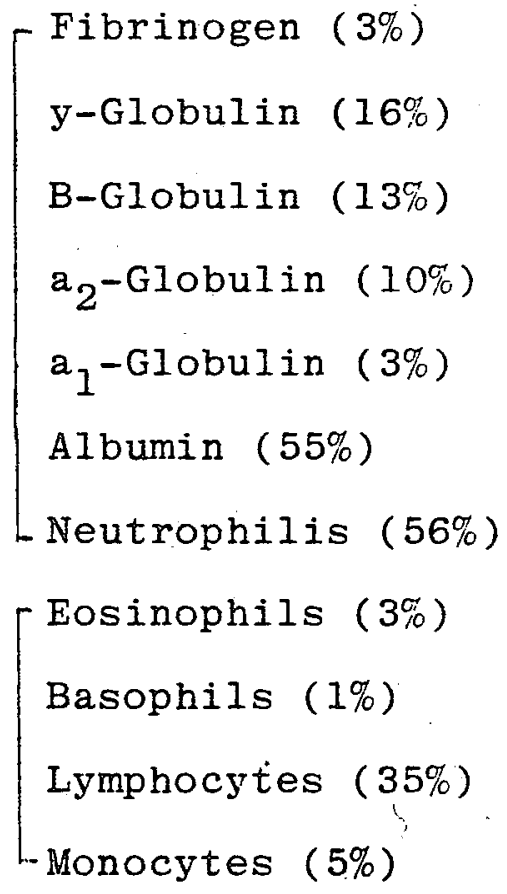

Figure 1. Major Components of Human Blood 
to $600,000 \mathrm{c} . \mathrm{mm}$. after delivery。 During labor the leucocyte count, which is about 10,000 per co mm。, rises to 20,000 to $30,000 \mathrm{c}$. $\mathrm{mm}$.

In this study, outdated blood was used. This blood was not old in the sense that it was dangerous if used. It was only "outdated;": for such blood was even used in Vietnam when it was outdated by six months. Outdated blood was useful for this study because it was readily available, easy to use, and, importantly, has some similarity to lochia since both have lost their clotting mechanism.

\section{$\frac{\text { Definition of Terms "Heavy," "Moderate," }}{\text { and "Slight" Blood Loss }}$}

In discussing blood loss, the nursing literature lacks specific definitions of the terms "heavy," "moderate," and "slight" but states that the amount of saturation is to be noted. Pillitteri (1977) and Lipkin (1978) stated that the source of the blood should be noted along with color, character, and odor. The nursing literature only considers subjective estimation of blood loss (Campbell, 1977; Bethea, 1973; Cole, 1975)。 The term "heavy" is discussed; it is generally defined as "excessive" and accompanied by clots (Bethea, - 1973; Broadribb and Corliss, 1973)。 Hamilton (1975, p. 157) stated that "if more than three pads become saturated in 15 minutes, the flow is excessive." Bleeding after delivery is profuse and, according to Hamilton (1975), this is very "normal" bleeding. Broadribb and Corliss 
(1973, p. 206) stated that moderate lochia is "usual and a peripad will be fairly well covered with blood in about one hour." They also continued that it is "normal to cover two peripads with blood in an hour and still have moderate blood loss." The discrepancies abound. The terms are unclear, undefined, and ambiguous, and because of this it is difficult for nurses to mean the same thing when they use the terms "heavy," "moderate," or "slight。"

\section{Difficulties in Estimating Blood Loss}

In order to be more precise, nurses sometimes estimate blood loss in $c^{\prime} \mathrm{s}$, but how accurate are these estimates? Pillitteri (1977) is the only one from the nursing literature to admit that there is difficulty in estimating blood loss. She stated that the difficulty arises in that nurses do not know how much blood it takes. to saturate a perineal pad. She stated the figure to be somewhere between 25 and $50 \mathrm{cc}^{\prime} \mathrm{s}$. The medical literature (Alderman, 1975; Clarke, Topley, and Flear, 1955; Buchman, 1953; Steward and Rourke, 1938) revealed that estimating blood loss is extremely difficult and inaccurate.

A specific amount of blood loss frequently tends to be underestimated in the clinical situation and the validity of reports based on observations may be disputed (Bonica and Lyter, 1951; Brant, 1967). Estimating blood loss is not exact; there are wide margins of error, and 
blood loss tends to be underestimated during obstetrical emergencies as well as routine procedures. Read and Anderton (1977) concluded in their study of 30 patients who had caesarean section that blood loss was underestimated. Wallace (1967) studied obstetrical blood loss with 835 patients and stated that using visual assessment at delivery was misleading because blood loss was always underestimated. He used a hemoglobin dilution technique to measure blood loss. Moir and Wallace (1967) also used this technique, along with visual estimation of 214 patients who had forceps delivery, and stated clearly that visual estimation was much lower than the actual blood loss. Blanchette (1977) also used this technique with his 100 clients and concluded that visual estimation was much lower than the actual blood loss. Brant (1967), with a 57 random sample population, stated that actual blood lost determined by hemoglobin djlution technique was approximately twice the amount estimated. Ueland (1976), p. 672) studied 75 "normal pregnant women" and concluded:

We have grossly underestimated parturition blood loss for years and present data should direct our attention to a measurable and meaningful parameter rather than the antiquated educated guess.

According to Thornton et al。(1963, p。92), "subjective estimation of visual assessment is extremely uncertain and should not be relied upon in any but the fittest of adult patients for the simplest operation. . ." 
Nurses are primarily responsible for the assessment of blood loss after delivery and in the postpartum period. It is the nurse who usually is the first one to make the judgment that bleeding is heavy, moderate, or slight. One needs to be cognizant of the fact that there are many discrepancies in the literature on exactly how much blood loss is occurring with various obstetrical procedures (Table 1). This can be concluded by looking at the varying amounts of blood lost during specific obstetrical procedures and being aware that a combination of factors may also occur. Health care providers do not have an accurate method or tool to measure the amount of blood loss other than the accepted practice of assigning a subjective evaluation term such as "heavy," "moderate," or "slight。"

\section{Methods of Determining Blood Loss}

There are many ways to directly or indirectly determine blood loss. These are summarized in Table 1. A brief description of each method follows (Gray and Nunn, 1971):

Direct Ways of Determining Blood Loss

Direct methods for determining blood loss are:

Measurement of blood loss by suction: Blood is trapped in a jar or a suction apparatus and is readily visible. Inaccuracies in measurement can arise as a result of the large area of cross-section of the average suction container. These inaccuracies can be reduced by having a 
Table 1. Summary of Obstetrical Blood Loss Studies

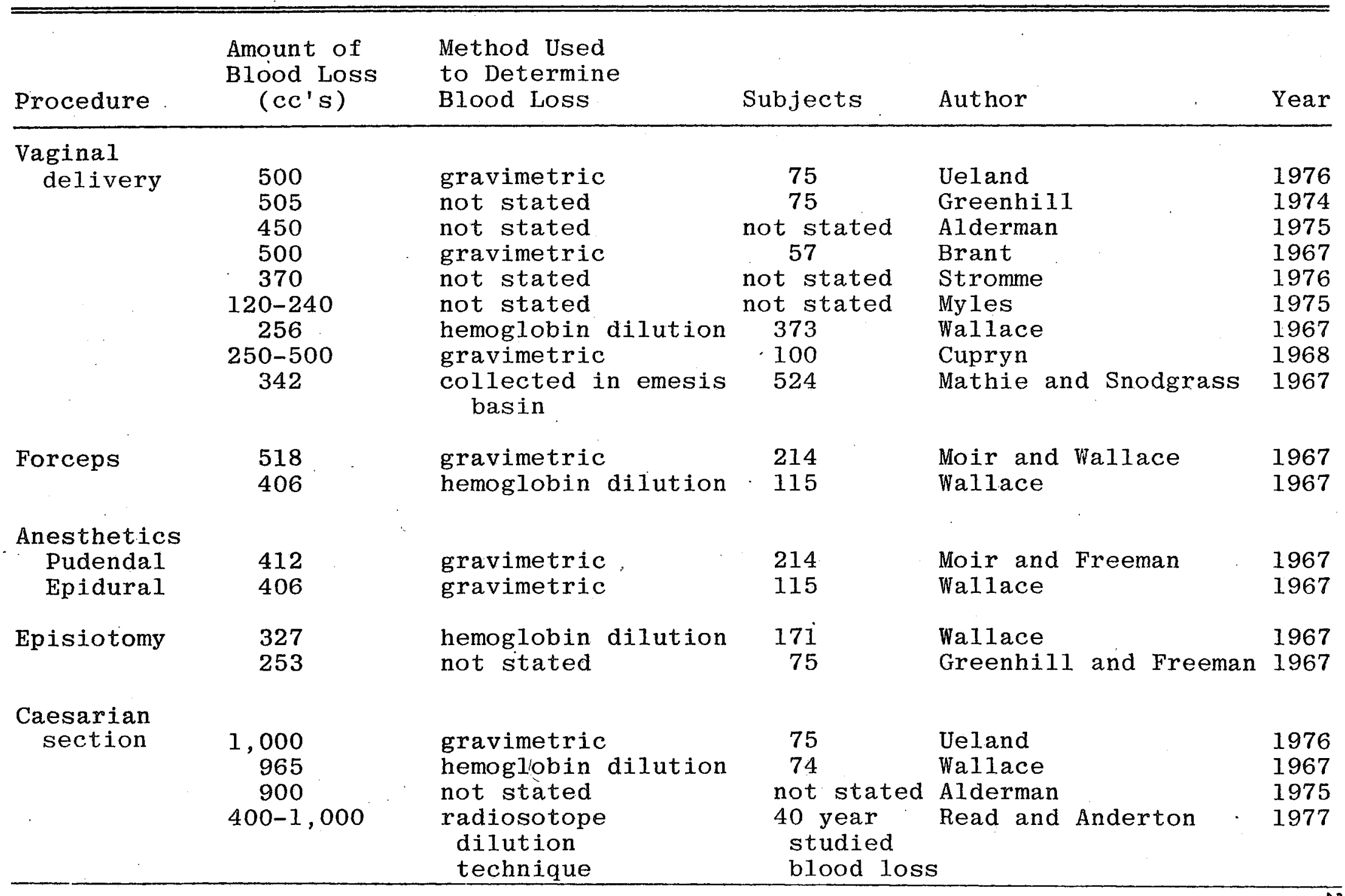


measuring cylinder in the suction line and at the same time filling it with a small quantity of defoaming agent or by weighing the suction bottle along with the swabs。

Gravimetric method. This method originally necessitated the use of dry swabs, although it can be modified so that'swabs may be moistened with known quantities of saline. It is based on the use of sponges, packs, towels, or linen employed for collecting blood during the operation and weighing after use. A weighing scale accurate to 0.1 gm is used. Dry sponges and packs do not have to be weighed before each operation or procedure because they are remarkably uniform in weight. The items should be weighed as soon as possible so that evaporation is minimized.

Electrolyte conductivity. Automatic blood loss meters have been produced based on the principle of electrolyte conductivity. This method can be employed for estimating loss in "suckers" for washed swabs and from bladder washing. This method has the advantage of giving a continuous estimate of blood loss provided all the blood loss is contained. Since it relies upon the constancy of the constituents of the blood and/or urine, exrors can arise.

Colorimetric method. Blood can be extracted by various means from swabs, lysed, and the hemoglobin concentration of the resultant solution can be used to determine 
the actual blood loss. The method relies on the constancy of the blood hemoglobin concentration during the course of the operation or procedure, and discrepancies can arise if this factor alters because of the hemodilution (Bond, 1969). This method was first employed with manual washing. Roe, Gardiner, and Dudley (1962), Thornton et al. (1963), and Mainland (1966) used automatic washing machines. The washing of the blood-contaminated swabs requires placing them in a washing machine with a known volume of tap water, to which has been added sufficient ammonium hydroxide to give a $1: 1,000$ dilution, and a defoaming agent. During the operation, swabs, blood from the suction apparatus, towels, and other articles are added and the concentration of the resultant solution determined. With a knowledge of the patient's hemoglobin concentration, and the volume of the water bath, a value for the blood loss is readily calculated.

$$
\begin{aligned}
& \mathrm{Hb}(\mathrm{g} / 100 \mathrm{ml}) \text { washing fluid } \mathrm{X} \\
& \underset{(\text { in } \mathrm{ml})}{\mathrm{Blood}}=\frac{\text { volume washing fluid (ml) }}{\mathrm{Hb}(\mathrm{g} / 100 \mathrm{ml}) \text { patient's } \mathrm{Hb} \mathrm{X}} \\
& \text { dilution factor patient's } \mathrm{Hb}
\end{aligned}
$$

Radioactivity of blood loss. A small known quantity of isotope is injected intravenously prior to the procedure (Murray and Potts, 1960). The blood loss is measured by the radioactivity of blood on swabs collected 
during the course of an operation. This technique requires time, expensive apparatus, and there is leakage of tracer into non-vascular compartments。

Indirect Ways of Determining Blood Loss

Indirect methods of determining blood loss are:

Subjective estimation. Subjective estimation by visual assessment is extremely uncertain. It is the method used by most nurses to determine blood loss. This method is inexpensive, rapid, and continuous, and it is used in major accident surgery, at least as a guide for preliminary blood transfusion.

Patient weighing. A large weighing table can be used to measure the pre- and post-operative weight of the patient. During surgery, it is difficult to assess the blood balance concurrently with blood loss. Allowances must be considered for drains, infusions, insensible water loss, and removal of tissue. The method depends upon the accuracy of the machine. Patient weighing serves as a useful check for other methods。

Vital signs. Vital signs consisting of blood pressure, temperature, pulse, and respirations are common methods used by nurses to assess blood status and loss in their clients. Vital signs are extremely useful in 
assessing infection, dehydration, body temperature, and cardio-pulmonary status.

After delivery, it has been proven that if there is a significant drop in blood pressure, already $1,200 \mathrm{ml}$ of blood has been lost (Stromme, 1976). In ectopic pregnancy, gradual vaginal bleeding occurs, and a drop in blood pressure and a rapid pulse may not be present; yet, the client may be developing shock (Bethea, 1973).

Hematocrit and hemoglobin. According to the literature, hematocrit readings on admissions are indirect and not exact (Blanchette, 1977)。Although a decrease in blood volume occurs with blood loss, the chemical composition of the blood may stay the same (Steward and Rourke, 1938)。 Neither the hematocrit or the hemoglobin concentration can be relied upon to give an indication of the degree of blood loss during the acute stage. This demonstrates the fallacy of assuming quantitative relationships between changes in hemoglobin or plasma and changes in plasma volume。

Urinary output. Catheterization and the measurement of urinary output on a time basis will give a good indication as to whether the patient has reduced circulating blood volume, provided that the kidney function has not been impaired. Bladder infection is a common complication, however。 
The central venous pressure. By measuring the pressure on the right side of the heart and relating this to the systemic arterial pressure, an estimate can be obtained of the ability of the heart to pump blood against peripheral resistance and cope with blood being presented to it. It is also a measure of venous return. The normal central venous pressure (CVP) varies between 5 and $12 \mathrm{~cm}$ $\mathrm{H}_{2} \mathrm{O}$. A high central venous pressure with a low systemic arterial pressure suggests that the cause of the hypotension is failure of the heart. A low central venous pressure with a low systemic arterial pressure is suggestive of reduced circulating blood volume, and indicates transfusion. However, the CVP is an invasive procedure having serious potential complications; therefore, it is not routinely used。

Problems accompany the use of each of the indirect methods of determining blood loss, and in many rural areas laboratory work and specialized equipment may not be available. It also follows that one may not even consider doing a hematocrit or other indirect measure of blood loss if the amount of loss is underestimated, as can occur with a slight blood loss over a long period of time.

The literature supports the fact that vital signs, hematocrit, and subjective estimation of blood loss are inadequate in determining blood loss. Nurses have to contend with ambiguous terms such as "heavy," "moderate," 
and "slight." This is the state of the art in modern maternity care。 
CHAPTER 3

\section{RESEARCH METHODOLOGY}

This chapter defines the design of the study, the selection of the sample and setting, the method of data collection, and the method of data analysis.

\section{Research Design}

This descriptive study was designed to determine the accuracy that registered nurses have in estimating blood loss and whether years of experience and education increases the degree of accuracy. It was designed to determine if nurses underestimate, as suggested by the literature, or overestimate blood loss. This study was also designed to explore the amount of blood loss in cubic centimeters that nurses consider heavy, moderate, or slight。

\section{Access to Research Setting}

Approval of the research protocol was obtained from the University of Arizona's Ethical Review Committee (Appendix A). Further approval was obtained from the Associate Director of Nursing for Research of a medical center for access to nurses at the medical center utilized. Access to the second institution used as a second research 
setting was accomplished through approval of the Assistant Director of Nursing at that medical center.

\section{Sample and Setting}

A convenience sample of 42 registered nurses was used. The subjects were required, as part of their job description, to estimate blood loss on a daily basis.

The following areas within two local Tucson hospitals were used: labor, delivery, postpartum, operating room, and emergency room. The study took place on each individual unit. A cart was set up with 20 peripads. The pads were numbered 1 through 20 and contained certain amounts of measured blood on them. Each facility had its own brand of peripad; one facility used Curity, the other used Tomac. When the pads were soaked, the Curity pad held $80 \mathrm{cc}$ 's of blood and the Tomac pad held $120 \mathrm{cc}$ 's of blood. The brand of peripad of the facility was used with the staff of that facility. However, in this study only 80 cc's of blood was used since the Curity pad was saturated by this amount. Peripad number 20 contained this amount of blood. The nurses who used the Tomac pads also saw $80 \mathrm{cc}$ 's of blood on their item 20. They were informed that the Tomac pad, when saturated, contained $120 \mathrm{cc}^{\prime} \mathrm{s}$ of blood.

Both day and evening staff members participated when possible. The study was conducted between 3 and 4 
p.m. in all areas except the operating rooms where it was conducted between 9 and 11 a.m. Each subject came at his/ her convenience.

\section{Method of Data Collection}

Arrangements were made with the American Red Cross to save the outdated blood. Arrangements were also made with each depártment head to assess appropriate dates to conduct the study. and to present the format and purpose of the study. Data were collected between March and April 1980 。

Consent of the subjects was obtained by virtue of their completion of the estimation study. The verbal presentation, as well as a written disclaimer, included the following: that approximately 15 minutes of their time was needed to complete the study, the reason for the study, assurance of confidentiality by using no names and anonymity of all responses, that refusal to participate would incur no negative consequences. Each group was informed that this was whole outdated blood which was on the peripads and they could pick up the pads if they so desired; that the correct answers to the amount of blood on the peripad would be given when each subject was finished answering the questions (Appendix B). 


\section{Development of the Instrument}

The instrument of collecting data was an information sheet which first requested demographic data of the participants, including age, sex, basic nursing education, highest degree or level of education obtained, number of years in estimating blood loss, and specialty area where the nurses worked. It next asked the nurses when they first learned to estimate blood loss and how they estimate (Appendix B). It was hoped that by asking these questions cognitive style might be learned.

The recording sheet was developed and used by this investigator in a prior estimation study of 40 subjects (Higgins, 1978). The recording sheet was used for recording data with ease and clarity. This recording sheet was also used to record data for this study (Appendix C). The subjects looked at 20 numbered peripads with a set amount of blood on each peripad which were displayed on a cart. The subject used the recording sheet by checking the box as to whether the amount of blood on each item was heavy, moderate, or slight. The nurse also recorded his or her estimate of blood in cubic centimeters. The correct amount of blood for each of the pads is listed in Appendix D.

\section{Data Analysis}

The techniques of descriptive statistics were utilized to organize the quantitative information in a 
concise and convenient form and analyze the data in a fashion that makes for ease of interpretation (Roscoe, 1969)。

Two other tests were utilized to determine relationships between groups. The t-test was used to determine whether the mean for 2 groups differ from each other significantly。 Chi-square tests were utilized to determine whether 2 nominal measures are related. This test was used to determine the relationship of over- and underestimation to to education, years of experience, and methods of estimating blood loss. The data on the information sheet were analyzed to obtain the following statistics for the nurses in this study:

1. The range and mean of ages of the nurses in the sample。

2. The percentage of males and females.

3. The percentage of nurses who initially graduated from diploma, associate degree, or baccalaureate programs.

4. The percentage of nurses who have a higher degree than the baccalaureate.

5. The range, mean, median, and percentage of the number of years in estimating blood loss.

6. The percentage of nurses who work in labor, delivery, postpartum, emergency room, and operating room.

7. Categorization of responses as to when nurses first learned to estimate. 
8. Any recurrent themes on how nurses learn to estimate.

The data on the recording sheet were analyzed to obtain the following statistics:

1. The number of subjects selecting each item as heavy, moderate, or slight。

2. The range, mean, and standard deviation of subjects' estimates of heavy, moderate, or slight for each item.

3. The mean, standard deviation, and mean error in the estimate of blood in cubic centimeters.

4. Overall t-test for differences between the actual amount and the estimated amount of blood on the peripads。

5. The frequency of response as to (heavy, moderate, slight; made by associate degree, diploma, and baccalaureate nurses) mean, standard deviation, chi square, and percentage they over- or underestimate blood loss。

6. The responses as to (heavy, moderate, slight; made by nurses cross-tabulated by years of experience) mean, standard deviation, chi square, and pertentage that they over- or underestimate blood loss.

7. The responses made by each department as to heavy, moderate, slight, mean, standard deviation, and 
percentage that they over- or underestimate blood loss.

8. The responses as to how nurses learned to estimate blood as to heavy, moderate, slight, mean, standard deviation, t-test, chi square, and percentage that they over- or underestimate blood loss.

9. The chi square and percentage of under- and overestimation in relation to when nurses first learned to estimate blood loss. 
CHAPTER 4

\section{PRESENTATION AND ANALYSIS OF DATA}

This chapter presents the statistical analysis of the data collected from the study described in the previous chapters. First, the demographic characteristics of the population are discussed. This is followed by a presentation of the data showing the degree of accuracy exhibited by nurses in determining blood loss. The last section presents data related to overestimation and underestimation of blood loss。

\section{Demographic Characteristics of the Population}

A total of 42 registered nurses participated in the study. All met the requirements of the study by estimating blood loss on a daily basis. Table 2 gives the characteristics of the sample in relation to age and number of years of experience in estimating blood loss. For the 42 subjects, the age range was between 20 and 48 years. The mean age was 29.4 years, with the median age at 27.5 years. The standard deviation was 6.9 years from the mean. The years of experience varied from no experience to 30 years with the mean at 6.4 years, median at 4 years. The standard deviation was 6.8 years. To compare the sample size 
Table 2. Age and the Number of Years of Experience in Estimating Blood Loss

\begin{tabular}{lrccccc}
\hline & N & Range & Mean & $\begin{array}{l}\text { Standard } \\
\text { Deviation }\end{array}$ & Median & $\begin{array}{l}\text { Per- } \\
\text { centage }\end{array}$ \\
\hline Age & 42 & $20-48$ & 29.4 & 6.9 & 27.5 & \\
$\begin{array}{l}\text { Years of } \\
\text { Experience }\end{array}$ & & & & & & \\
$0-2$ & 12 & $0-30$ & 6.4 & 6.8 & 4.0 & \\
$3-5$ & 14 & & & & & 29.0 \\
$5-10$ & 10 & & & & & 33.0 \\
$>10$ & 6 & & & & & 24.0 \\
& & & & & & 14.0 \\
\hline
\end{tabular}

according to years of experience in estimating blood loss, the groups were divided as: $0-2$ years had 12 nurses (29 percent), 3-5 years had 10 nurses (24 percent), and > 10 years had 6 nurses (14 percent)。 The group of nurses from 0-10 years of experience showed no significant difference in cell size. The group > 10 years experience was significantly different.

Table 3 gives the characteristics of the sample in relation to sex and education. There were 3 male ( 7 percent) and 39 female (93 percent) nurses who participated in the study. Most of the nurses were educated in baccalaureate (43 percent) and/or associate degree ( 36 percent) programs. Only 21 percent of the nurses came from diploma schools. Out of the entire sample, 1 diploma nurse 
Table 3. Demographic Characteristics of the Sample in Relation to Sex and Education

\begin{tabular}{lll}
\hline \hline & $N$ & Percentage \\
\hline
\end{tabular}

$\underline{\text { Sex }}$

Male

Female
3

39
7.0

93.0

Education

Associate degree

Diploma

15

36.0

Baccalaureate

21.0

18

(2 percent) went back to school to complete a baccalaureate degree other than nursing。

Specialty areas, or work sites, are areas where the nurses usually work. These areas were chosen because the nurses, are required to estimate blood loss on a daily basis in their job or specialty area. In the hospital, these areas were selected: operating room, emergency room, recovery room, postpartum, labor, and delivery. In this study, all àreas were used except the recovery room. Table 4 gives the work sites of the 42 nurses who work in the hospital and estimate blood loss on a daily basis. Sixteen nurses ( 38 percent) worked in the operating room, 11 nurses (26 percent) worked in the emergency room. A t-test was 
Table 4. Specialty or Work Site Where Nurses Estimate Blood Loss on a Daily Basis

\begin{tabular}{lrlrll} 
& & $\begin{array}{l}\text { Per- } \\
\text { centage }\end{array}$ & t-test & df $\begin{array}{c}\text { Prob- } \\
\text { ability }\end{array}$ \\
\hline Operating room & 16 & 38.0 & & & \\
Emergency room & 11 & 26.0 & -3.17 & 38 & 0.005 \\
Obstetrics & 15 & 36.0 & & & \\
$\quad$ Postpartum & 7 & 17.0 & -0.23 & 38 & 0.25. \\
Labor and delivery & 8 & 19.0 & -0.23 & \\
\hline
\end{tabular}

done to evaluate the difference in estimates of blood loss for these two groups. Results showed that there is a significant differences, $p=0.005$, for the operating and emergency room nurses. In the postpartum group, there were 7 nurses (17 percent) who participated; from labor and delivery there were 8 nurses (19 percent)。A t-test was done between the means of these two groups of nurses. There was no significant difference $(p=0.25)$. Therefore, the postpartum labor, and delivery groups were combined and became "obstetrics" with a sample of 15 nurses (36 percent). The cell sizes for specialty areas were compatible. Nurses were asked when they first learned to estimate blood loss. Table 5 categorizes their responses to this question. Most of the nurses reported they learned to estimate in school ( 41 percent) or on the job 
Table 5. Categorization of Responses As To When Nurses First Learned to Estimate

\begin{tabular}{lrr}
\hline \hline Response & N & Percentage \\
\hline School & 17 & 41.0 \\
On the job (gave the year) & 14 & 33.0 \\
Time frame (garned & 4 & 14.0 \\
Never learned & 1 & 10.0 \\
Could not remember & & 2.0 \\
\hline
\end{tabular}

(33 percent). Six nurses (14 percent) answered by giving the year they began to estimate. This can be viewed as experience. Four nurses (10 percent) stated they never learned and $I$ nurse ( 2 percent) could not remember.

The nurses were asked how they learned to estimate blood loss. Table 6 lists these themes. Six nurses (14 percent) stated that they usually estimate by weighing the items. Seven nurses ( 17 percent) guess and 15 nurses (36 percent) use observation as a criterion for estimating. Nine nurses (2I percent) taught themselves to estimate and 5 nurses ( 12 percent) asked someone on the job, such as another nurse of an anesthesiologist for their opinion. A t-test was done between the following groups: (1) weighed and guessed, (2) guessed and observed, (3) observed and taught self or asked others。 As indicated in Table 6, there are significant differences between the means for each of the groups. 
Table 6. Methods by which Nurses Learn to Estimate Blood Loss

\begin{tabular}{lrccc}
\hline Response & $N$ & Percentage & t-test & Probability \\
\hline Weighing & 6 & 14.0 & 3.89 & 0.0005 \\
$\begin{array}{l}\text { Guessing } \\
\text { Observations }\end{array}$ & 75 & 17.0 & & \\
$\begin{array}{l}\text { Taught self } \\
\text { Asked others }\end{array}$ & 9 & 21.0 & -1.71 & 0.10 \\
$\quad \begin{array}{l}\text { on the job } \\
\quad \text { as peer or }\end{array}$ & 5 & 12.0 & -3.65 & 0.0005 \\
$\quad$ anesthesiologist) & & & & \\
\hline
\end{tabular}

\section{Degree of Accuracy in Determining Blood Loss}

Registered nurses were asked to examine and to record if the measured amount of blood on 20 peripads was heavy, moderate, or slight. They were asked to record the amount of blood on the pad in cubic centimeters $\left(c c^{3} s\right)$.

Table 7 shows the actual amount of blood on each peripad as well as the lack of agreement in use of the terms "heavy," "moderate," or "slight。" The number of nurses selecting the amount of blood as heavy, moderate, or slight can be noted. It also shows the range of $\mathrm{cc}^{\mathrm{s}} \mathrm{s}$ thought to be heavy, moderate, or slight for each peripad. The actual range of blood on the peripads was from 5-80 $\mathrm{cc}^{\mathrm{i}} \mathrm{S}$ 。 The estimated range of blood on the peripads was 
Table 7. Blood on 20 Peripads Estimated as Heavy, Moderate, or Slight $(N=42)$

\begin{tabular}{|c|c|c|c|c|c|}
\hline \multirow{2}{*}{$\begin{array}{l}\text { Item } \\
\text { Number }\end{array}$} & \multirow{2}{*}{$\begin{array}{l}\text { Actual } \\
\text { Number } \\
\text { of cc's } \\
\text { on } \\
\text { Peripad }\end{array}$} & \multicolumn{3}{|c|}{$\begin{array}{l}\text { Number of Subjects } \\
\text { Selecting Each Category }\end{array}$} & \multirow{2}{*}{$\begin{array}{l}\text { Range of } \\
\text { Estimates } \\
\text { in cc's }\end{array}$} \\
\hline & & Heavy & Moderate & Slight & \\
\hline 1 & 25 & 0 & 30 & 12 & $5-150$ \\
\hline 2 & 5 & 0 & 1 & 41 & $2-100$ \\
\hline 3 & 65 & 19 & 21 & 2 & $15-250$ \\
\hline 4 & 30 & 1 & 39 & 2 & $10-175$ \\
\hline 5 & 45 & 9 & 32 & 1 & $12-200$ \\
\hline 6 & 20 & 2 & 22 & 18 & $8-150$ \\
\hline 7 & 55 & 16 & 23 & 3 & $14-200$ \\
\hline 8 & 35 & 5 & 32 & 5 & $13-200$ \\
\hline 9 & 60 & 24 & 18 & 0 & $19-300$ \\
\hline 10 & 25 & 1 & 30 & 11 & $14-125$ \\
\hline 11 & 55 & 27 & 15 & 0 & $22-200$ \\
\hline 12 & 15 & 0 & 9 & 33 & $4-105$ \\
\hline 13 & 45 & 13 & 27 & 2 & $12-250$ \\
\hline 14 & 40 & 5 & 37 & 0 & $10-175$ \\
\hline 15 & 10 & 0 & 4 & 38 & $5-105$ \\
\hline 16 & 50 & 12 & 27 & 3 & $18-200$ \\
\hline 17 & 20 & 0 & 30 & 12 & $9-125$ \\
\hline 18 & 5 & 0 & 0 & 42 & $3-60$ \\
\hline 19 & 15 & 0 & 14 & 28 & $8-110$ \\
\hline 20 & 80 & 40 & 1 & 1 & $4-500$ \\
\hline
\end{tabular}


from 2-500 ccs.s. There was one instance of total agreement to the amount of blood on a peripad. This was on item 18 which had $5 \mathrm{cc}^{\prime} \mathrm{s}$ of blood. All nurses thought this was slight blood loss. The estimated range of blood loss was 3-60 cc $\mathrm{cs}^{\mathrm{s}}$. A lack of agreement can be noted for item 3 which contained $65 \mathrm{cc}^{\text {'s }}$ on the peripad。 Nineteen nurses estimated this amount as heavy。 Twenty-one nurses estimated this amount as moderate, and 2 nurses estimated this amount as slight. The estimates ranged from $15-250 \mathrm{cc}^{\prime} \mathrm{S}$ 。

Table 8 shows the actual amount of blood on each peripad and the range of blood in $c c^{\prime} s$ as estimated by the 42 subjects. It shows the estimate of heavy blood loss included varying amounts, ranging from 8 to $500 \mathrm{cc}$ 's。 Estimates for moderate were specified all the way from 5 to $250 \mathrm{cc}^{\mathrm{i}} \mathrm{s}$. Estimates for slight varied from $2-150 \mathrm{cc}^{\prime} \mathrm{s}$ 。 It can be noted from item 1 that 30 nurses estimated 25 $\mathrm{cc}^{\mathrm{i}} \mathrm{s}$ of blood to be moderate and their estimates ranged from 1 to $150 \mathrm{cc}^{\prime} \mathrm{s}$. Twelve nurses estimated this same amount (25 $\mathrm{cc}^{\circ} \mathrm{s}$ ) as slight blood loss and their estimate ranged from $15-100 \mathrm{cc}^{\mathrm{i}} \mathrm{s}$ 。

As indicated in Table 9, there is a significant difference between the overall actual mean of the blood on the peripads $(\bar{x}=35)$ and the overall mean of the amount estimated by the sample $(\bar{x}=70.51)$. A t-test confirms the significant difference between the means $(p=0.0005)$. The mean error is calculated to normalize and compare the data. 
Table 8. Range of Blood Estimated as Heavy, Moderate, or Slight

\begin{tabular}{|c|c|c|c|c|c|c|c|}
\hline \multirow{2}{*}{$\begin{array}{l}\text { Item } \\
\text { Number }\end{array}$} & \multirow{2}{*}{$\begin{array}{l}\text { Actual } \\
\text { Number } \\
\text { of } \mathrm{cc}^{\prime} \text { s on } \\
\text { Peripad }\end{array}$} & \multicolumn{6}{|c|}{$\begin{array}{c}\text { Range of Subjects' Estimates for } \\
\text { (in } c^{\prime} s \text { ) }\end{array}$} \\
\hline & & Heavy & $N *$ & Moderate & $N^{*}$ & Slight & $N^{*}$ \\
\hline 1 & 25 & --- & 0 & $5-150$ & 30 & $15-100$ & 12 \\
\hline 2 & 5 & --- & 0 & 6 & 1 & $2-100$ & 41 \\
\hline 3 & 65 & $15-250$ & 19 & $20-250$ & 21 & $25-100$ & 2 \\
\hline 4 & 30 & 17 & 1 & $10-175$ & 39 & $30-75$ & 2 \\
\hline 5 & 45 & $16-40$ & 9 & $12-200$ & 32 & 100 & 1 \\
\hline 6 & 20 & $8-150$ & 2 & $12-155$ & 22 & $12-100$ & 18 \\
\hline 7 & 55 & $20-200$ & 16 & $1.4-200$ & 23 & $80-150$ & 3 \\
\hline 8 & 35 & $50-200$ & 5 & $13-175$ & 32 & $20-125$ & 5 \\
\hline 9 & 60 & $19-300$ & 24 & $22-200$ & 18 & --- & 0 \\
\hline 10 & 25 & 125 & 1 & $14-100$ & 30 & $15-125$ & 11 \\
\hline 11 & 55 & $22-200$ & 27 & $25-200$ & 15 & --- & 0 \\
\hline 12 & 15 & --- & 0 & $15-100$ & 9 & $4-105$ & 33 \\
\hline 13 & 45 & $50-250$ & 13 & $12-175$ & 27 & 100 & 2 \\
\hline 14 & 40 & $20-120$ & 5 & $10-175$ & 37 & --- & 0 \\
\hline 15 & 10 & $--\infty$ & 0 & $7-100$ & 4 & $5-105$ & 38 \\
\hline 16 & 50 & $18-120$ & 12 & $18-200$ & 27 & $75-80$ & 3 \\
\hline 17 & 20 & --- & 0 & $9-125$ & 30 & $12-50$ & 12 \\
\hline 18 & 5 & $--\infty$ & 0 & -- & 0 & $3-60$ & 42 \\
\hline 19 & 15 & --- & 0 & $8-70$ & 14 & $8-110$ & 28 \\
\hline 20 & 80 & $40-500$ & 40 & 35 & 1 & 65 & 1 \\
\hline
\end{tabular}

$* N=$ number of subjects estimating each category 
Table 9. Differences between the Actual Amount and Mean Estimate of Blood

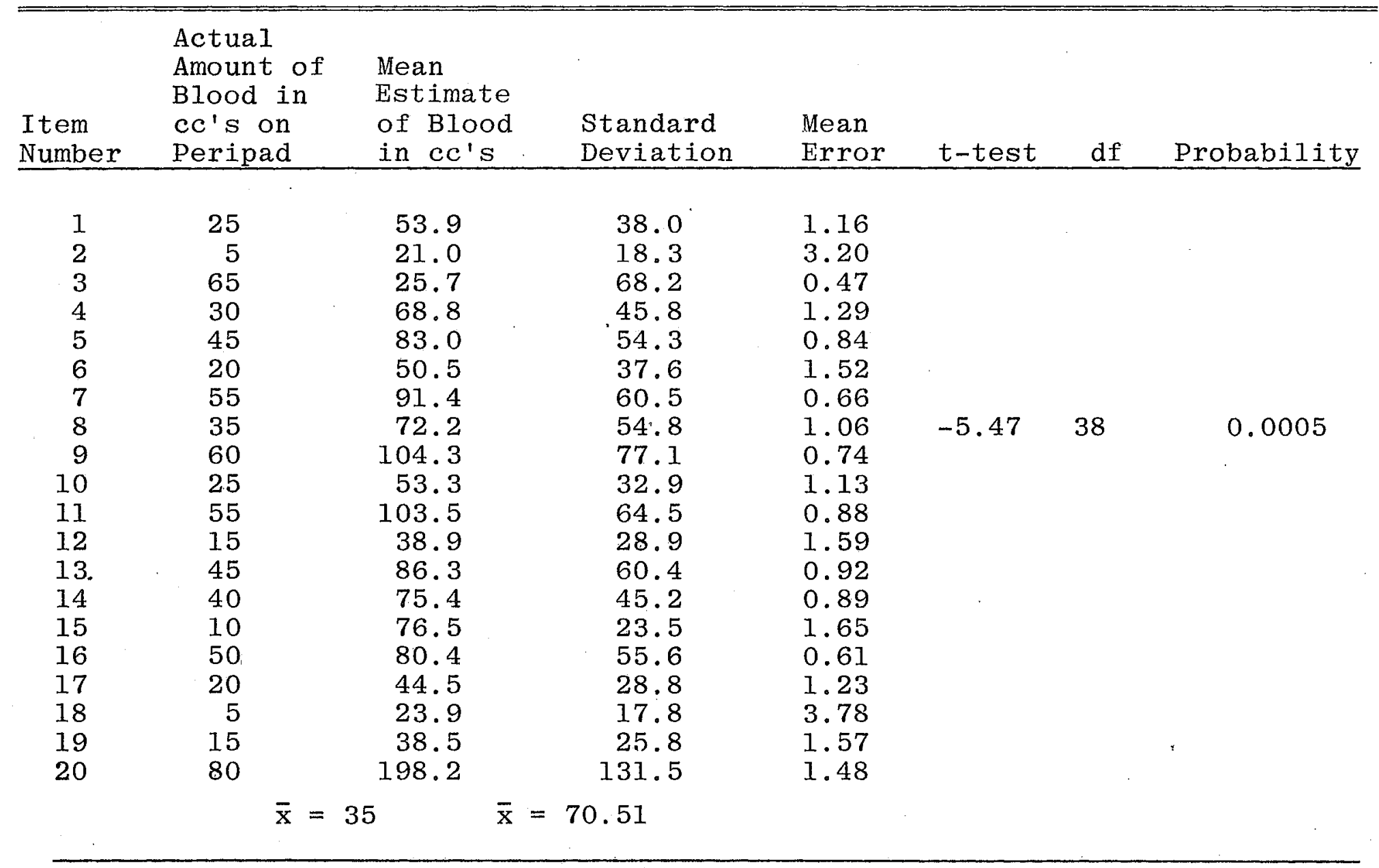


It looks at the mean of the actual and estimated blood (Higgins, 1980). It can be noted that the mean error is significantly high for the entire 20 items.

Figure 2 shows the mean error in estimating the amount of blood on each peripad versus the actual amount of blood. The mean error is defined by

$$
E=\frac{\bar{x}-x_{c}}{x_{c}}
$$

where

$$
\begin{aligned}
& \mathrm{E}=\text { mean error } \\
& \overline{\mathrm{x}}=\text { mean estimate for a particular item } \\
& \mathrm{x}_{\mathrm{C}}=\text { actual amount of blood on the item. }
\end{aligned}
$$

This expression provides a convenient normalization of the amount of error in each estimate: A value of zero for mean error indicates that the estimate is exact. A positive value indicates an overestimate while a negative value indicates an underestimate (Higgins, 1980)。

Let us now consider how consistent the errors are. For this purpose, all estimated measures are graphed in Figure 1. As can be seen in Figure 2, the mean error is positive in every case, indicating overestimates. However, the level of error is not constant for every item. It varies substantially depending upon the actual amount of blood. At small amounts (less than $10 \mathrm{cc}^{\prime} \mathrm{s}$ ), the mean error exceeds 1.5 (or the estimate is greater than 150 


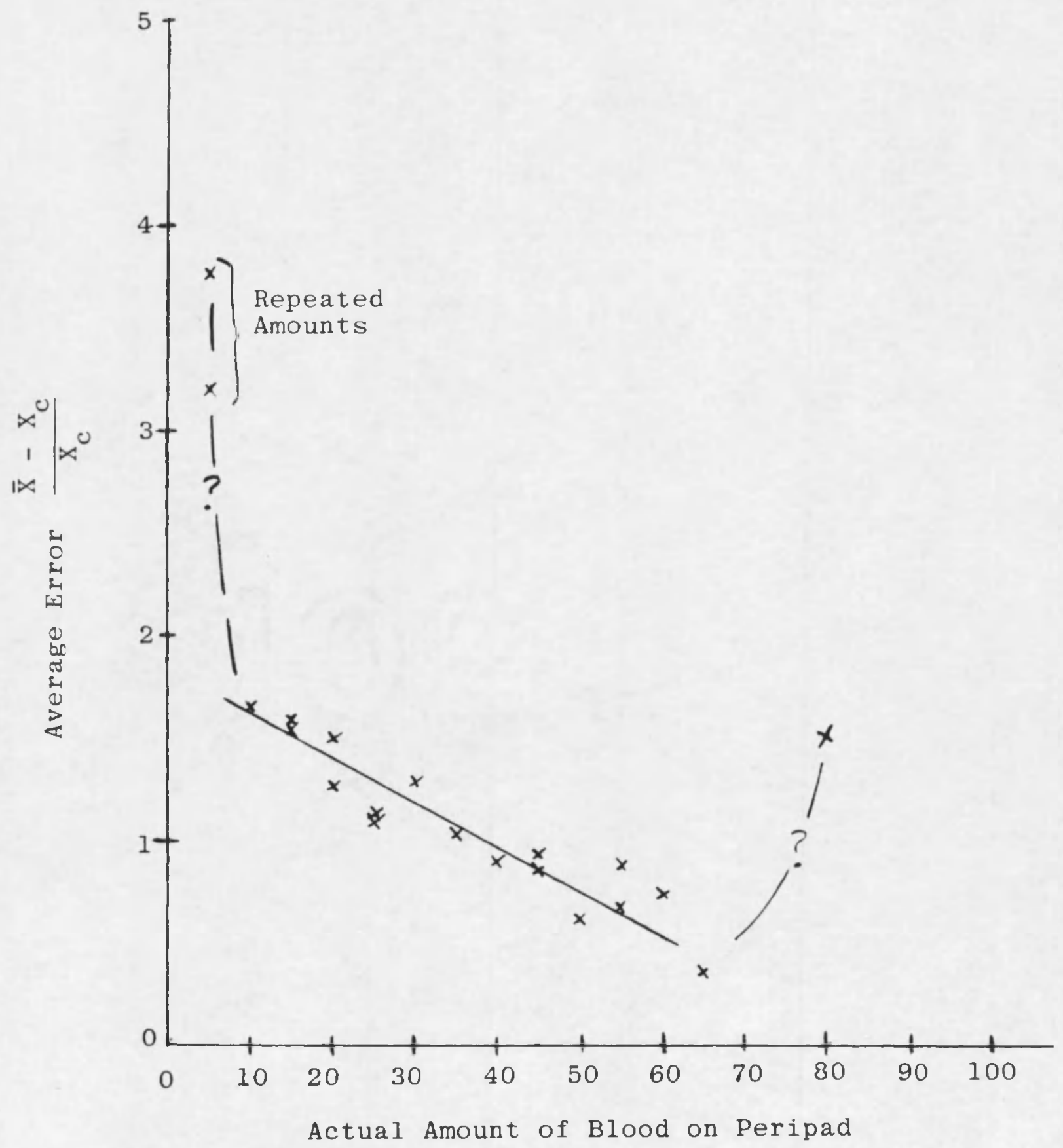

Figure 2. Average Error versus Actual Amount of Blood 
percent high). At high amounts of blood (greater than 60 $c c^{\prime} \mathrm{s}$ ), the mean error is less than 0.5 (or the estimate is less than 50 percent high)。 Overall, all estimates are quite high (average of 100 percent high) but the amount of overestimate diminishes with increasing amounts of blood in a regular linear fashion. This conclusion breaks down, however, at very small and very large amounts of blood. As also can be seen in Figure 2, the mean errors for the actual amount of blood of $5 \mathrm{cc}^{\prime} \mathrm{s}$ and $80 \mathrm{cc}^{\prime} \mathrm{s}$ are very high (more than 300 percent at $5 \mathrm{cc}^{\prime} \mathrm{s}, 150$ percent at $\left.80 \mathrm{cc}^{\prime} \mathrm{s}\right)$. These errors are well out of line with the errors at the other blood amounts. For this reason, question marks are placed in Figure 2 to denote the discrepancies at the very small and very large amounts of blood. Emphasis is placed on this fact because it appears that nurses recognize very small or very large amounts of blood, but they lose ability to estimate quantitatively at these levels。

It is important to note that there were $4 \mathrm{blood}$ amounts which were repeated $\left(5,20,45\right.$, and $\left.55 \mathrm{cc}^{\prime} \mathrm{s}\right)$. These repeated values are exhibited in Figure 2 by two $x^{\prime} s$ plotted at the same actual blood value. In general, the nurses were consistent in estimating the same amounts of blood. However, with $5 \mathrm{cc}^{\prime}$ s of blood the mean error of estimation is widely spread (320 percent and 378 percent). This spread is apparently due to the nurses' difficulty in estimating very small or very large amounts of blood. 
Forty-two nurses participated in the study. Table 10 shows the number of correct responses made by the nurses. It also shows the relationship of education, experience, exposure area, and when and how nurses first learned to estimate. Only 1 nurse ( 2 percent) had 5 out of 20 correct responses. This nurse held an associate degree with 22 years of experience. She worked in obstetrics and first learned to estimate in school and then taught herself to estimate. Seven nurses (16 percent) had 2 correct responses. Seven nurses ( 16 percent) had 1 correct response and 27 nurses (67 percent) made no correct responses. Overall, only 15 nurses of the 42 had any correct responses. The correct responses ranged from 1 to 5 out of 20 possible responses。 Of the nurses with at least one correct response, 7 were educated in baccalaureate programs. Seven came from diploma schools and 1 was educated in an associate degree program. Experience ranged from 1 month to 30 years. Eight nurses worked in obstetrics. Six worked in the operating room, and 2 worked in the emergency room. Of the nurses in this group, 8 first learned to estimate blood loss in school, 3 on the job, 1 used a time frame (experience) and 3 never learned. The nurses learned to estimate blood loss by: teaching themselves (6), guessing (2), asking others (2), observations (4), and weighing the item (1)。 Table 10 shows the vast amount of differences among the nurses. Education, years of experience, exposure area, 
Table 10. Number of Correct Responses Made by 42 Nurses with Pre-measured Blood on 20 Peripads

\begin{tabular}{|c|c|c|c|c|c|c|c|c|c|c|c|}
\hline $\begin{array}{l}\text { Number of } \\
\text { Correct } \\
\text { Responses }\end{array}$ & $\mathbf{N}$ & $\begin{array}{l}\text { Per- } \\
\text { centage }\end{array}$ & Education & No. & $\begin{array}{l}\text { Years } \\
\text { of Expe- } \\
\text { rience }\end{array}$ & $\begin{array}{l}\text { Speciality } \\
\text { Area }\end{array}$ & No. & $\begin{array}{l}\text { When First } \\
\text { Jearned How } \\
\text { To Estimate }\end{array}$ & No. & $\begin{array}{l}\text { How Learned } \\
\text { To Estimate }\end{array}$ & No. \\
\hline 5 & 1 & 2 & Associate Degree & 1 & 22 & Obstetrics & I & School & 1 & Self-taught & 1 \\
\hline 2 & 7 & 16 & $\begin{array}{l}\text { Diploma } \\
\text { Baccalaureate }\end{array}$ & $\begin{array}{l}3 \\
4\end{array}$ & $1-30$ & $\begin{array}{l}\text { Operating Room. } \\
\text { Emergency } \\
\text { Obstetrics }\end{array}$ & $\begin{array}{l}3 \\
1 \\
3\end{array}$ & $\begin{array}{l}\text { School } \\
\text { On the job } \\
\text { Never } \\
\text { Time frame } \\
\text { ( } 30 \text { years ago) }\end{array}$ & $\begin{array}{l}2 \\
3 \\
1 \\
1\end{array}$ & $\begin{array}{l}\text { Guessing } \\
\text { Asking others } \\
\text { Self-taught } \\
\text { Weighing } \\
\text { Observation }\end{array}$ & $\begin{array}{l}2 \\
1 \\
2 \\
1 \\
1\end{array}$ \\
\hline 1 & 7 & 16 & $\begin{array}{l}\text { Associate Degree } \\
\text { Diploma } \\
\text { Baccalaureate }\end{array}$ & $\begin{array}{l}0 \\
4 \\
3\end{array}$ & $1 \mathrm{mo}$. & $\begin{array}{l}\text { Operating Room } \\
\text { Emergency } \\
\text { Obstetrics }\end{array}$ & $\begin{array}{l}3 \\
1 \\
4\end{array}$ & $\begin{array}{l}\text { School } \\
\text { Never learned }\end{array}$ & $\begin{array}{l}5 \\
2\end{array}$ & $\begin{array}{l}\text { Asked others } \\
\text { Self-taught } \\
\text { Observation }\end{array}$ & $\begin{array}{l}1 \\
3 \\
3\end{array}$ \\
\hline 0 & 27 & 67 & $\begin{array}{l}\text { Associate Degree } \\
\text { Diploma } \\
\text { Baccalaureate }\end{array}$ & $\begin{array}{r}8 \\
8 \\
11\end{array}$ & $0-21$ & $\begin{array}{l}\text { Operating Room } \\
\text { Emergency } \\
\text { Obstetrics }\end{array}$ & $\begin{array}{r}10 \\
10 \\
7\end{array}$ & $\begin{array}{l}\text { School } \\
\text { On the job } \\
\text { Time frame } \\
\text { Cannot } \\
\text { remember } \\
\text { Never }\end{array}$ & $\begin{array}{r}10 \\
10 \\
5 \\
1 \\
1\end{array}$ & $\begin{array}{l}\text { Guessing } \\
\text { Asked others } \\
\text { Self -taught } \\
\text { Weighing } \\
\text { Observation }\end{array}$ & $\begin{array}{r}5 \\
2 \\
4 \\
5 \\
11\end{array}$ \\
\hline
\end{tabular}


and when and how nurses learned to estimate blood loss has no direct correlation to the number of correct responses.

\section{Data Related to Overestimation and Underestimation of Blood Loss}

The 42 registered nurses in this study tended to overestimate blood loss. Each nurse made 20 responses with a total of 840 responses. Figure 3 gives the percentage of nurses who over- and underestimated blood loss. Thirty nurses (71 percent) overestimated blood loss and 10 nurses (25 percent) underestimated blood loss. Table 11 gives the estimation percentages for over- and underestimating for the sample and relationship to education, specialty area, and experience.

It can be noted in Table 11 that the educational preparation of the nurses with no correct answers included 9 from associate degree programs, 15 from diploma schools, and 18 from baccalaureate programs. Also, the nurses tended to overestimate regardless of educational preparation.

Nurses with over 2 years of experience $(N=30)$ tend to overestimate, and those with less than 2 years of experience $(\mathrm{N}=12)$ equally underestimate ( 47 percent) and overestimate ( 47 percent)。. The nurses in all specialty areas tend to overestimate. No group of nurses were more accurate than any other group of nurses. The nurses in the operating room overestimated by 54 percent and underestimated by 


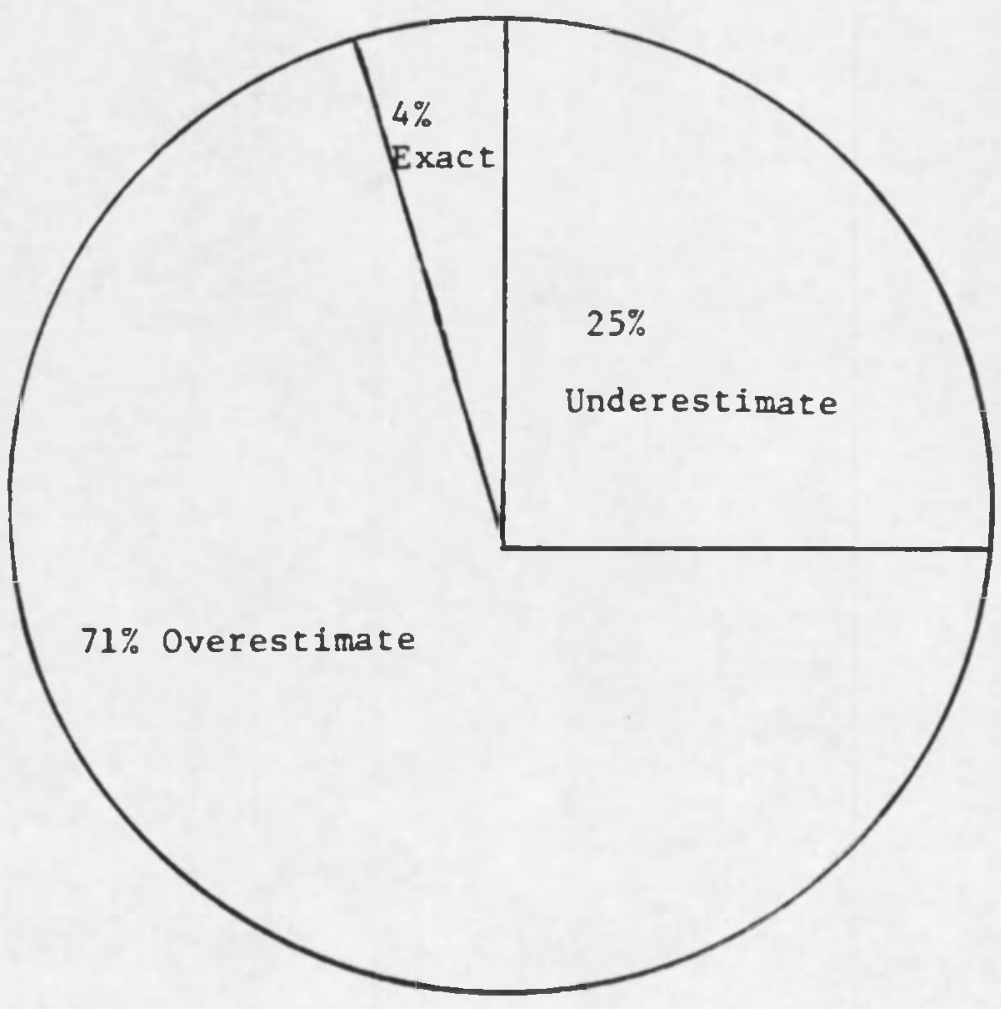

Figure 3. Percentage of 42 Nurses Who Overand Underestimate Blood Loss 
Table 11. Estimation Percentages and Relationship to Education, Experience, and Specialty Area

\begin{tabular}{|c|c|c|c|c|c|c|}
\hline & \multirow[b]{2}{*}{$\mathrm{N}$} & \multicolumn{2}{|c|}{ Estimation } & \multirow[b]{2}{*}{ Chi Square } & \multirow[b]{2}{*}{$\mathrm{df}$} & \multirow[b]{2}{*}{ Probability } \\
\hline & & Under & Over & & & \\
\hline \multicolumn{7}{|l|}{ Education } \\
\hline $\begin{array}{l}\text { Associate degree } \\
\text { Diploma } \\
\text { Baccalaureate }\end{array}$ & $\begin{array}{r}9 \\
15 \\
18\end{array}$ & $\begin{array}{l}37.0 \\
27.0 \\
18.0\end{array}$ & $\begin{array}{l}60.0 \\
70.0 \\
77.0\end{array}$ & 115.33 & 2 & 0.05 \\
\hline \multicolumn{7}{|l|}{ Years of experience } \\
\hline $\begin{array}{r}1-2 \\
3-5 \\
5-10 \\
>\quad-10\end{array}$ & $\begin{array}{r}12 \\
14 \\
10 \\
6\end{array}$ & $\begin{array}{r}47.0 \\
25.0 \\
8.0 \\
14.0\end{array}$ & $\begin{array}{l}47.0 \\
73.0 \\
89.0 \\
80.0\end{array}$ & 102.75 & 3 & 0.05 \\
\hline Specialty area & & & & & & . \\
\hline $\begin{array}{l}\text { Operating room } \\
\text { Emergency room } \\
\text { Obstetrics }\end{array}$ & $\begin{array}{l}16 \\
11 \\
15\end{array}$ & $\begin{array}{r}42.0 \\
5.0 \\
22.0\end{array}$ & $\begin{array}{l}54.0 \\
91.0 \\
74.0\end{array}$ & 0.4388 & 2 & 0.05 \\
\hline
\end{tabular}


42 percent. However, nurses in the emergency room overestimated by 91 percent.

A chi-square test was done to analyze over- and underestimation in relation to education, years of experience, and specialty areas. The chi-square tests were nonsignificant $(p=.05)$. This test confirms that nurses, regardless of education, years of experience, and specialty areas, may be considered alike in the way that they estimate blood loss.

Nurses were asked when and how they first learned to estimate. These responses were evaluated by percentages in over- and underestimation (Table 12). Regardless of when or how nurses learn to estimate, the trend is to overestimate. The one exception is the 6 nurses who stated that they had learned to estimate by weighing. They underestimate (64 percent) rather than overestimate (35 percent) blood loss. The chi-square tests indicated that the differences were not statistically significant. Therefore, the nurses, regardless of when and how they first learned to estimate, may be considered alike in the way they estimate and alike in that their estimates are biased upward. 
Table 12. Estimation Percentages and Relationship As to When and How Nurses First Learned to Estimate Blood Loss

\begin{tabular}{llll}
\hline \hline & Estimation & & \\
& $\begin{array}{l}\text { Over Under } \\
\text { (Percentage) }\end{array}$ & Chi \\
Square df Probability
\end{tabular}

When did you first learn to estimate?

$\begin{array}{lrrrrrr}\text { In school } & 17 & 18.0 & 78.0 & & & \\ \text { On the job } & 15 & 37.0 & 61.0 & 36.23 & 2 & 0.05 \\ \text { Never learned } & 4 & 41.0 & 50.0 & & & \end{array}$

How did you first learn to estimate?

$\begin{array}{lrrrrrr}\text { By guessing } & 7 & 10.0 & 84.0 & & & \\ \text { By observation } & 15 & 10.0 & 88.0 & & & \\ \text { By teaching self } & 9 & 33.0 & 60.0 & 100.05 & 4 & 0.05 \\ \text { By asking others } & 5 & 34.0 & 62.0 & & & \\ \text { By weighing } & 6 & 64.0 & 35.0 & & & \end{array}$




\section{DISCUSSION OF THE STUDY}

This chapter includes a discussion of the analysis of the data including the degree of accuracy in estimating blood loss, the assignment of the labels "heavy," "moderate," and "slight," and the tendency toward over- and underestimation of blood loss. The nursing implications of this study are presented. Finally, recommendations are given for further study of determination of blood loss by estimation.

\section{Analysis of Data Relating to the Degree of Accuracy in Estimating Blood Loss}

Forty-two registered nurses participated in the study and were asked to record if the set amount of blood on 20 peripads was heavy, moderate, or slight. They were also asked to record the estimate of blood in cubic centimeters. The data confirmed that nurses are not accurate in estimating blood loss. They were consistently wrong。 With few exceptions, the greatest disagreement occurred with categorization of the smaller and larger amounts of blood. It is stated in the nursing literature that estimating blood is difficult and nurses do not know the amount of blood on a soaked peripad. Pillitteri (1977) stated 
that a soaked peripad holds between 25 and $50 \mathrm{cc}^{\prime}$ s of blood. This study showed that $80 \mathrm{cc}^{\prime} \mathrm{s}$ was on a soaked Curity pad and $120 \mathrm{cc}^{\prime} \mathrm{s}$ on a Tomac pad. It is also true that when set amounts of blood were repeated on peripads, the nurses had difficulty and were not consistent in estimating.

The criteria for the subjects was that they were registered nurses and estimated blood on a daily basis. The nurses ${ }^{8}$ educational background varied with most of the nurses coming from baccalaureate and associate degree programs. Experience ranged from 1 month to 30 years. The nurses' specialty or work site was evenly distributed among the operating room, emergency room, and obstetrics. Obstetrics included postpartum, labor, and delivery。 only 3 male nurses participated in the study, making it impossible to draw any conclusions about any sex differences in estimation.

There is no significant relationship between the degree of accuracy and education, years of experience, and exposure in blood estimating. Further, there is no apparent improvement with an increase in these factors.

- Responses were evaluated in relation to when nurses first learned to estimate. These responses were as follows: school, on the job, the year first learned, never learned, and could not remember. This evaluation showed no relation between accuracy and when nurses first learned to estimate blood loss. 
Responses were also evaluated in relation to how nurses learned to estimate: weighing, guessing, observation, self-taught, and asked others on the job such as a peer or an anesthesiologist. This evaluation also showed no relation between accuracy and method of learning. It is conceivable that because nurses receive little or no feedback as to how accurately they estimate, education, experience, exposure, when and how they learned has no effect on their ability to estimate accurately.

$$
\frac{\text { What Nurses Consider Heavy, Moderate, }}{\text { and Slight Blood Loss }}
$$

The literature shows that the terms "heavy," "moderate," and "slight" are unclear, undefined and ambiguous and because of this it is difficult for nurses to mean the same thing when they use these terms. This study confirmed the literature base because there was only one instance of total agreement on a peripad which contained $5 \mathrm{cc}^{\prime} \mathrm{s}$ of blood. The overlap in the number of $\mathrm{cc}^{\prime} \mathrm{s}$ between each of the three categories was considerable for each of the items. The nurses had difficulty determining whether the amount of blood was heavy, moderate, or slight. The overall ranges for heavy, moderate, and slight for all items were 8-500 $\mathrm{cc}^{\prime} \mathrm{s}, 5-250 \mathrm{cc}^{\prime} \mathrm{s}$, and 2-125 $\mathrm{cc}^{\prime} \mathrm{s}$. A large discrepancy exists about what entails heavy, moderate, and slight blood loss. 
Analysis of Data As It Relates To

Over-and Underestimation

The literature states that estimating blood loss is not exact; there are wide margins of error, and blood loss tends to be underestimated. This study shows that nurses' estimates are biased upward because they have the tendency to overestimate blood loss. It was quite a difficult challenge to estimate small and large amounts of blood on a peripad (Figure 2). These amounts were consistently overestimated. This may not be random since a peripad was a thick absorbent item. The degree of dispersion or the amount of absorbency appears to affect the estimate.

\section{Nursing Implications}

The data indicated that the problem of estimating blood loss is twofold. Not only were the murses in this study unable to estimate blood loss in $\mathrm{cc}^{\prime} \mathrm{s}$, but there was also disagreement as to how much was heavy, moderate, or slight. With the need for a more scientific foundation in nursing, there is a critical need to assess what the nurse is reading concerning what constitutes heavy, moderate, or slight blood loss. If nurses cannot differentiate between these categories, how can they believe the accuracy of their data base in general?

Nurses are developing physical assessment skills and rely daily on their observation skills. Yet this study 
makes one question the accuracy with which nurses are recording the amount of drainage on dressings, peripads, or linens. It is even more disquieting that the data indicated that the smaller and greater the amount of blood, the greater was the amount of:error in estimation.

These results raise further questions, and have definite implications for nursing practice. One may ask what difference it makes if blood loss is estimated inaccurately. One might as well ask, why bother accurately measuring any drainage. Why not just guess! There is no dispute that it is extremely important to accurately determine fluid losses when caring for critically ill or pediatric clients. Blood contains fluids, proteins, and electrolytes; should not we reconsider the methods used to determine its loss? The literature does not address the safe limit of error when determining blood loss, and further research is needed before we learn the full impact of inaccurate estimation.

This study also has implications for nursing education. The findings lead one to believe that nurses are lacking adequate instruction on determining blood loss. Schools of nursing and inservice departments should consider strategies aimed at teaching nurses to accurately determine blood loss. These teaching strategies based on the conceptual framework of this study should consider that estimation is based on perceptual features such as the size, 
thickness, and absorbency of the peripad and how much blood is on the pad. Each nurse estimates based on his/her cognitive style. Since there is such diversity in perceptual and cognitive style, two teaching strategies should be utilized: (1) a factual slide tape presentation, and (2) actual hands-on experience.

A slide tape presentation needs to be developed and used. It should present the facts and scientific data based on estimation. This would include the process, methods, and discrepancies in estimating blood loss. Using a slide tape presentation would facilitate the learning of the scanner, convergent thinker, and the field independent person. There is a need to stop the tape periodically throughout the presentation and ask questions of the audience. This facilitates learning in the focuser, divergent thinker, and field dependent person.

The other teaching strategy to facilitate learning of the estimation process would be to follow up the slide tape presentation with an actual hands-on experience in estimating blood loss. Nurses have difficulty in estimating because they have not been taught to estimate accurately. Nurses need to see and be told the actual amounts of blood on peripads. They need to put set amounts of blood on peripads and see the dispersion, expecially with small (< $10 \mathrm{cc}^{\prime} \mathrm{s}$ ) and large amounts ( $\left.>60 \mathrm{cc}^{\prime} \mathrm{s}\right)$. They need to be given every opportunity to estimate blood loss 
and then weigh the pad and get immediate feedback. This process is necessary so that nurses can become more accurate in estimating. The fact that nurses were consistent (though in error) in estimating repeated samples of blood suggests that they can learn actual amounts easily. It is most important that nurses be taught rules of thumb, such as, a soaked Curity pad holds $80 \mathrm{cc}$ 's of blood. By using the hands-on experience for nurses, they can be shown the relationships between amounts, and this helps them to perceive and develop sound principles of estimation based on their own cognitive style.

There are many unanswered questions, and further research in the area of estimating blood loss is planned. But until such time, nurses need to reappraise the reliability of the methods they now use to determine blood Ioss.

\section{Recommendations for Future Study}

The findings of this study indicated that nurses have difficulty in estimating amounts of blood on peripads. Overall, the estimates were high on the average by 100 percent. There was a distinct trend, however, of . increasing accuracy with large amounts of blood (150 percent high at $10 \mathrm{cc}^{\prime} \mathrm{s} ; 50$ percent high at $\left.60 \mathrm{cc}^{\prime} \mathrm{s}\right)$. This trend breaks down at very $\operatorname{small}\left(5 \mathrm{cc}^{\prime} \mathrm{s}\right.$ ) and very large amounts ( $80 \mathrm{cc}$ 's) where the nurses overestimate. 
Recommendations for future nursing study include:

1. Replicate this study with a larger sample of males, as well as physicians.

2. Teach nurses how to estimate and then follow up with investigation of how accurate they are in estimating.

3. Develop a tool to assess various cognitive styles in relation to estimation. 
CHAPTER 6

\section{SUMMARY}

The study described in the preceding chapters was an attempt to further the knowledge about the accuracy that nurses have in estimating blood loss. The conceptual framework for this study was based on the concepts of the physilogical processing of perceived information and cognitive process from psychology. These concepts were interrelated to determine the processes that one goes through in accurately estimating blood loss.

\section{Purpose of the study}

The purpose of this study was to attempt to answer the following questions:

1. How accurate are nurses in estimating blood loss?

2. Do nurses tend to overestimate or underestimate blood loss?

3. What is the range, in $\mathrm{cc}^{\prime} \mathrm{s}$, of blood loss for heavy Ioss?

4. What is the range, in $\mathrm{cc}^{\prime} \mathrm{s}$, of blood loss for moderate loss?

5. What is the range, in ce's, of blood loss for slight loss? 
The problem which was explored in the study was to determine the degree of accuracy exhibited by nurses in determining blood loss. This problem is significant to health professionals because maternal mortality results from intra- and postpartum hemorrhage, and the amount of blood loss cannot be assessed by vital signs.

The literature summarized in the study reviews the composition of whole blood, definitions of heavy, moderate, and slight blood loss, difficulties in estimating blood loss and methods of determining blood loss. Many references confirmed the difficulty of estimating and the fact that most professionals underestimate blood loss. However, the terms "heavy," "moderate," and "slight" are unclear, undefined, and ambiguous, therefore making it difficult for nurses to mean the same thing when they use these terms.

\section{Methodology}

A descriptive design was used to determine the accuracy that registered nurses have in estimating blood loss and whether years of experience, education, and specialty area increases the degree of accuracy. A convenience sample of 42 registered nurses was used. The subjects were required as part of their job on a daily basis to estimate blood loss. The subjects looked at 20 numbered peripads with a set amount of blood on each peripad. The subjects checked the box on the recording sheet as to whether the 
amount of blood on each item was heavy, moderate, or slight. The nurse also recorded his or her estimate of blood in cubic centimeters.

\section{Findings}

Descriptive statistics were used to determine the accuracy of nurses in estimating blood loss-what nurses consider heavy, moderate, or slight, and over- and underestimation. A t-test was used to analyze the means between specialty area and recurrent themes on how nurses learned to estimate. The significance level for all analyses was between 0.10 to 0.0005 . There were significant differences between the means of these groups.

Chi square was used to see if the over- and underestimation of groups were statistically significant. Chi square indicated that there was no significant difference between the nurses regardless of education, experience, exposure, and how and when the nurses first learned to estimate。

\section{Conclusions}

The findings of this study indicated that there was even disagreement as to what constituted heavy, moderate, or slight blood loss. Both over- and underestimation occurred. Of the nurses participating in the study, 71 percent overestimated and 25 percent underestimated blood loss. There was no significant relationship between 
accuracy and education, years of experience, specialty area, or when and how nurses learned to estimate blood loss. It can be concluded from this study that in general the nurses (I) overestimated blood loss; (2) had significant difficulty in estimating very small and very large amounts of blood, (3) although in error, were consistent in estimating repeated samples with the same amounts of blood, (4) were not consistent in estimating what they considered heavy, moderate, or slight blood loss.

\section{$\underline{\text { Recommendations }}$}

Based on the findings of this study, the following recommendations were made:

1. Replicate this study with a larger sample of males, as well as physicians.

2. Teach nurses how to estimate and then follow up with an investigation of how accurate they are in estimating.

3. Develop a tool to assess various cognitive styles in relation to estimation. 


\section{ETHICAL REVIEW COMMITTEE APPROVAL}

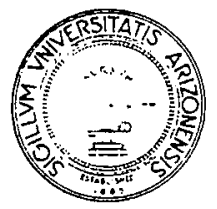

\section{THE UNIVERSITY O'F ARIZONA}

TUCSON. ARIZONA 85724

H L'MAY SU'BJECTS COMMITTEE ARIZONA HEAITH SCIF TCES CEVTER 2305

Patricia Higgins, R.N., BSN

College of Nursing

Arizona Health Sciences Center

Dear Ms. Higgins:

We have reviewed your proposal entitled, "Measuring Nurses' Accuracy in Estimating Blood Loss", which was subritted to the Human Sub-" jects Comittee and concur with the Departmental Review Comittee's examination and recommendation of this minimal risk project. Therefore, approval is granted effective 14 February 1980.

Approval is granted with the understanding that no changes will be made in the procedures followed or the questionnarie used (copies of which we have on file) without the knowledge and approval of the Human Subjects Committee and the Departmental Review Committee. Any physical or psychological harm to any subject must also be reported to each committee.

Sincerely yours,

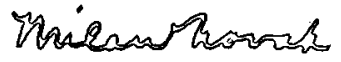

Milan Novak, M.D., Ph.D

Chairman

Human Subjects Committee

$\mathrm{MN} / \mathfrak{j} \mathrm{m}$

cc: Ada Sue Hinshaw, Ph.D.

Departmental Review Committee 
APPENDIX B

\section{DISCLAIMER SHEET}

You are being asked to voluntarily answer the questions on this information sheet. The purpose of this study is to determine what is heavy, moderate or slight blood loss. By responding to the questions, you will be giving your consent to participate in the study. Your name is not on the information sheet, and you may choose not to answer some or all of the questions, if you so desire. You may feel free to ask questions of the investigator at any time, and may feel free to withdraw or decline to participate without fear of incurring any difficulties. Confidentiality will be maintained throughout. Answers will be made available to you as soon as your group finishes recording their answers.

\section{GENERAL INFORMATION}

Age

Sex.M F

In what type of program did you receive your basic nursing education:

Diploma Associate Baccalaureate

What is the highest degree or level of education obtained?

Number of years in estimating blood loss

specialty area in which you work

When did you first learn to estimate blood loss?

How did you learn to estimate? 
APPENDIX C

RECORDING SHEET

There are 20 peripads (items) with certain amounts of blood on them.

a) Check the column if the blood is heavy, moderate, or slight.

b) Write the amount of blood in cubic centimeters (cc's).

\begin{tabular}{|c|c|c|c|c|}
\hline Irem & Heavy & Poderate & Slight & Amount of Blood in $\mathrm{CC}^{\prime} \mathrm{s}$ \\
\hline 1 & & & & \\
\hline 2 & & & & \\
\hline 3 & & & & \\
\hline 4 & & & & \\
\hline 5 & & & & \\
\hline 6 & & & & \\
\hline 7 & & & & \\
\hline 8 & & & & \\
\hline 9 & & & & \\
\hline 10 & & & & . \\
\hline 11 & & & & \\
\hline 12 & & & & \\
\hline 13 & & & & . \\
\hline 14 & & & & \\
\hline 15 & & & & \\
\hline 16 & & & & . \\
\hline 17 & & & & \\
\hline 18 & & & & \\
\hline 19 & & & & \\
\hline 20 & & & & \\
\hline
\end{tabular}




\section{APPENDIX D}

\section{ANSWERS TO THE 20 ITEMS ON}

ESTIMATING BLOOD LOSS

Item

(Peripad)
Amount of Blood ( $\mathrm{cc}^{\prime} \mathrm{s}$ )

25

5

65

30

45

20

55

35

60

25

55

15

45

40

10

50

20

5

15

80 


\section{SELECTED BIBLIOGRAPHY}

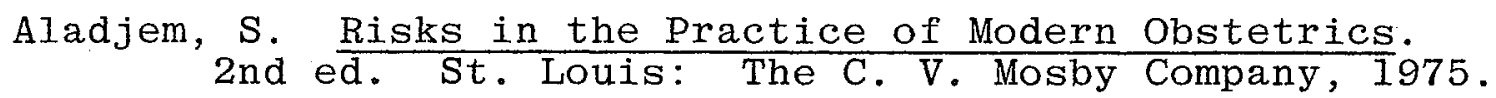

Alderman, M. M. "Prenatal Care: First Concerns in the Postpartum Period." Patient Care, (February 1, 1975), 58-73.

Atkinson, R. S., G. B. Rushman, and A. J. Lee. A Synopsis of Anaesthesia. 8th ed. Great Britain: John Wright and Sons, Ltd., 1977.

Bartlett, F. C. Remembering: An Experimental and Social Study. London: Cambridge University Press, 1932.

Bethea, D. C. Introduction to Maternity Nursing. 2nd ed. Philadelphia: Lippincott Company, 1973.

Bishop, C. Overview of Blood. Buffalo, New York: Blood Information Service, 1974 .

Bishop, C. Overview of Blood. Buffalo, New York: -Blood Information Service, 1978 .

Blanchette, H. "Electric Manual Exploration of the Uterus after Delivery: A Study and Review." Journal of Reproductive Medicine, 19 (July 1977), $\overline{13-16 .}$

Blumenthal, A. The Process of Cognition. Englewood Cliffs, New Jersey: Prentice-Ha11, 1977.

Bond, A. G. "Determination of Operative Blood Loss, the Sources of Error and Elimination of Inaccuracy in the Hemoglobin-Dilution Technique." Anaesthesia, 24 (1969), 219.

Bonica, J. J. and C. S. Lyter. "Measurement of Blood Loss During Surgical Operations." American Journal of Surgery, 81 (May 1961), 495-504.

Brant, H. A. "Precise Estimation of Post Partum Hemorrhage, Difficulties and Importance:" British Medical Journal, I (February 1967), 309-400.

Broadribb, V. and C. Corliss. Maternal-Child Nursing. Philadelphia: J. B. Lippincott Company, 1973. 
Buchman, M. "Blood Loss During Gynecological Operations.". American Journal of Obstetrics and Gynecology, 65 (January 1953), 53-59.

Campbel1, S. and J. Smith. "Postpartum Assessment Guide." American Journal of Nursing, (July 1977), 1179.

Clarke, R., E. Topley and C. T. Flear. "Assessment of Blood Loss in Civilian Trauma." The Lancet, 1 (March 26, 1955), 629-633.

Cole, R. Obstetrical Procedure Manual. St. Louis: The Catholic Hospital Association, 1975.

Copenhaven, E. "Operations Concerning Blood Loss During Vaginal Hysterectomy." Obstetrics and Gynecology, 24 (September 1964), 385-388.

Cupryn, J. "Uterine Contractibility in the Fourth State of Labor and Blood Loss at Delivery." American Journal of Obstetrics and Gynecology, 101 (June 15, 1968), $490-494$.

Duman, R. and S. Morgan. "EEG Assymetry as a Function of Occupation Task and Task Difficulty." Neuropsychologic, (1975), 219-228.

Dunn, S. R., J. S. Walker, D. L. Aston, and S. Cripps. "Effect of Anaesthetic Technique on Blood Loss in Termination of Pregnancy." British Journal of Anaesthesia 45 (June 1973), 633-637.

Elener, H. "Anesthetic Management of the Parturient in Hemorrhagic Shock." International Anaesthesiology Clinics, Vol. 6, No. 3(1968), 765-783.

Ellis, H. C. Fundamentals of Human Learning and Cognition. Duguque, Iowa: Brown, 1972.

Gray, T. C. and J. F. Nunn, eds. General Anesthesia, 3rd ed. New York: Appleton-Century-Crofts, 1971.

Greenhill, J. P. Obstetrics. Philadelphia: W. B. Saunders Company, 1965,940.

Greenhill, J. P. and E. A. Friedman. Biological Principles and Modern Practice of Obstetrics. Philadelphia: W. B. Saunders Company, 1974.

Guyton, A. Textbook of Medical Physiology. 4 th ed. Philadelphia: The C. V. Mosby Company, 1971. 
Hamilton, P. M. Basic Maternity Nursing. St. Louis: The C. V. Mosby Company, 1975 .

Hebb, D. O. The Organization of Behavior. New York: Wiley, 1949 .

Heuser, R. Fertility Tables for Birth Cohorts by Color. Department of Health, Education and Welfare. Publishing \#HRA 76-1152, 1973.

Higgins, C. J. Professor of Civil Engineering, University of New Mexico, Albuquerque. Personal interview. June 1, 1980.

Higgins, P. G. "Using the Principles of Change Theory--How Nurses Changed their Attitude in Determining Blood Loss." Unpublished paper to meet the requirements of Nursing 445 at The University of New Mexico, December, 1978 .

Kagen, J. and N. Kagen. Carmichael's Manual of Child Psychology, 3rd ed. P. H. Mussen (Ed.). New York: Wiley, 1970.

Klahr, D. and J. G. Wallace. Cognitive Development. New York: John Wiley and Sons, 1976.

Lazar, M. and H. Krieger. "Blood Loss in Vaginal Surgery: A Comparative Study." Obstetrics and Gynecology, 13 (June 1959), 707-710.

Lithtiger, M. and F. Moya. Introduction to the Practice of Anesthesia. New York: Harper and Row Publishers, 1972 .

Lipkin, G. Parent-Child Nursing-Psychosocial Aspects. 2nd ed. St. Louis: The C. V. Mosby Company, 1978.

Livingston, R. B. Sensory Processing, Perception, and Behavior. New York: Raven Press, 1978.

Louka, M. H. and G. C. Lewis. "Obstetric and Gynecological Bleeding." Hospital Medicine, (August 1976), 4449.

Mainland, J. F. "A Simple Photo-Electric Method for the Estimation of Blood Loss during Surgery." British Journal of Anesthesia, 38 (1966), 76. 
Mathie, I. K. and C. A. Snodgrass. "The Effect of Prophylactic Oxytocic Drugs on Blood Loss After Delivery." Journal of Obstetrics and Gynecology of the British Commonwealth, 74 (5) (October 1967), 653-662.

McManus, C. F. "Postpartum Hemorrhage Due to Hypofibrinogenemia." Nursing Mirror, (May 1, 1975), 69-72.

Modan, I., S. Kumar, and P. Misra. "Blood Volume in Accidental Hemorrhage." Journal of Obstetrics and Gynecology of India, 17 ( 1967$), 343-347$.

Moir, D. D. and G. Wallace. "Blood Loss at Forcepts Delivery." Obstetrics and Gynecology of the British Commonwealth, 74 (June 1967), 424-429.

Murray, B. R. P. and M. W. Potts. "Blood Volume Estimation: A Review of Methods." Guy's Hospital Gazette, 74 (1960), 120 .

Myles, M. Textbook for Midwives. 8th ed. London: Churchhil Livingston, 1975.

Piaget, J. The Psychology of Intelligence. New York: Harcourt, 1950 .

Piaget, J. The Child's Conception of Number. New York: Norton, 1965 .

Pillitteri, A. Nursing Care of the Growing Family--A Maternal-Newborn Text. Boston: Little Brown and Company, 1977 .

Plass, E. D., J. C. Litzenberg, and L. A. Calkins. "Management of the Third State of Labor with Special Reference to Blood Loss." American Journal of Obstetrics and Gynecology, 21 (February 1931), 172-177.

Read, M. D. and I. M. Anderton. "Radioisotope Dilution Technique for Measurement of Blood Loss Associated with Lower Segment Caesarean Section." British Journal of Obstetrics and Gynecology, 84 (November 1977), 859-861.

Rice, B. "Brave New World of Intelligence Testing." Psychology Today, (September 1979), 37-38. 
Roe, C. F., A. J. Gardner, and H. A. F. Dudley. "A Simple Instrument for Rapid, Continuous Determination of Operative Blood Loss." The Lancet, I (March 31, $1962), 672-673$.

Roscoe, J. Fundamental Research Statistics for the Behavioral Science. New York: Holt, Rinehart, and Winston, Inc., 1969.

Sprague, A. D. and V. Nagell, Jr. "The Relationship of Age and Endometrial Histology to Blood Loss and Morbidity Following Vaginal Hysterectomy." American

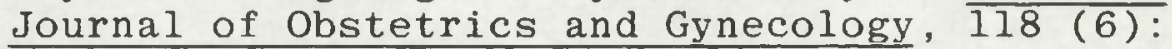
(March 15, 1974), 805-808.

Steward, I. D. and G. M. Rourke. "Changes in Blood and Interstitial Fluid Resulting from Surgical Operations and Ether Anesthesia." Journal of Clinical Investigation, 17 ( July 1938), 413-416.

Stromme, W. Operative Obstetrics. New York: AppletonCentury-Crofts, 1976.

Thornton, J. A., R. Saynor, H. G. Schroeder, D. G. Taylor, and D. Verel. "Estimating of Blood Loss with Reference to Cardiac Surgery." British Journal of Anaesthesia, 35 (1963), 91-99.

Tolman, E. C. "Determiners of Behavior at a Choice Point." Psychological Review, 45 (1938), 1-41.

Tolman, E. C. "Cognitive Maps in Rats and Men." Psychological Review, 55 (1948), 189-208.

Ueland, K. "Maternal Cardiovascular Dynamics." American Journal of Obstetrics and Gynecology, (November 1976), 671-677.

Van Foerster, H. Cognition: A Multiple View. ed. P. L. Garbin. New York: Spartan, 1970.

Wallace, G. "Blood Loss in Obstetrics Using a Hemoglobin Dilution Technique." Journal of Obstetrics and Gynecology of the British Commonwealth, (1967), 64-66.

Wingfield, A. Human Learning and Memory: An Introduction. New York: Harper and Row, 1979.

Yordan, E., J. Turk, and J. Petrie. "A Nearly Fatal Case of Placenta Percreta." American Journal of Obstetrics and Gynecology, (October 15, 1977), 462-463. 
